\title{
Techno-economic comparison of membrane distillation and MVC in a zero liquid discharge application
}

\author{
R. Schwantes ${ }^{\mathrm{a}, \mathrm{b}, \mathrm{c}, *}$, K. Chavan ${ }^{\mathrm{a}}$, D. Winter ${ }^{\mathrm{d}}$, C. Felsmann ${ }^{\mathrm{b}}$, J. Pfafferott ${ }^{\mathrm{c}}$ \\ ${ }^{\text {a }}$ SolarSpring GmbH, Germany \\ b TU Dresden, Germany \\ c Offenburg University of Applied Sciences, Germany \\ ${ }^{\mathrm{d}}$ Fraunhofer Institute for Solar Energy Systems, Germany
}

\section{A R T I C L E I N F O}

\section{Keywords:}

Membrane distillation

Zero liquid discharge

System design

Techno-economic analysis

\begin{abstract}
A B S T R A C T
Membrane distillation (MD) is a thermally driven membrane process for the separation of vapour from a liquid stream through a hydrophobic, microporous membrane. However, a commercial breakthrough on a large scale has not been achieved so far. Specific developments on MD technology are required to adapt the technology for applications in which its properties can potentially outshine state of the art technologies such as standard evaporation. In order to drive these developments in a focused manner, firstly it must be shown that MD can be economically attractive in comparison to state of the art systems. Thus, this work presents a technological design and economic analysis for AGMD and v-AGMD for application in a zero liquid discharge (ZLD) process chain and compares it to the costs of mechanical vapour compression (MVC) for the same application. The results show that MD can potentially be $\sim 40 \%$ more cost effective than MVC for a system capacity of $100 \mathrm{~m}^{3} /$ day feed water, and up to $\sim 75 \%$ more cost effective if the MD is driven with free waste heat.
\end{abstract}

\section{Introduction}

Membrane distillation is a thermal separation process which normally operates between 30 and $80^{\circ} \mathrm{C}[1,2,3]$ and can distill fresh water from wastewater. As the name suggests, membrane distillation uses hydrophobic membranes and a driving force temperature gradient (even capable of using low grade waste heat) [4] to bring about the evaporation of water. Since the issuing of the first MD patent by Bodell in 1963 [5], the utilization of membrane distillation has been investigated for a large variety of applications such as food and beverage processing $[6,7,8,9]$, concentration of sucrose solutions [10] textile industry effluent recycling $[11,12]$, municipal waste water treatment $[13,14]$, medical applications [15,16], removal of volatile organic compounds [17] or even treatment of radioactive wastewater solutions [18]. However, throughout the last 5 decades, the most common application has been desalination with a consensus amongst the community that brine concentration holds the highest potential within the scope of desalination for MD technology as presented in a systematic map review and survey by [19]. The potential of MD in desalination applications is shown in the progress of the more commercially orientated works targeted at MD module development and piloting $[20,21,22]$.
However, a commercial breakthrough on a large scale has not been achieved so far. The barriers for entering into existing markets are high with state of the art reverse osmosis (RO) and evaporation technology to compete against, in regard to cost effectiveness and process reliability. Triggered by increasingly strict environmental policies regarding the management of liquid effluents from various kinds of industrial processes, technologies are needed that can concentrate liquid discharge up to a near saturation level. Here, state of the art technology runs into limitations (high pressure in RO and corrosion in evaporators) that MD does not encounter due to the vapour pressure driven nature of the process and the polymeric materials used, thus providing a unique market opportunity and driver for the commercialization of the technology as a process step in low or zero liquid discharge (ZLD) chains [1].

Zero liquid discharge (ZLD) is a term that has gained quite a lot of attention in the past decade; first in the United States of America, followed by China, India and the rest of the world. ZLD is an ideal process where no liquid discharge leaves the plant boundary eliminating any kind of wastewater discharge and meeting environmental regulations [23]. However, the conventional thermal ZLD schemes practiced all over the world are fairly expensive; sometimes more than the main processing plant which has urged many to look for alternatives. ZLD

\footnotetext{
* Corresponding author at: SolarSpring GmbH, Christaweg 40, 79114 Freiburg im Breisgau, Germany.

E-mail address: rebecca.schwantes@solarspring.de (R. Schwantes).
} 
also should lead to recovery of water as water as a resource is becoming scarce on the one hand and its demand in the industrial sector is increasing on the other. In a constant struggle to reduce costs, minimizing use of resources and meeting environmental regulations in the process industry, installing a ZLD system might not seem like a correct choice to all industry owners; especially to those with smaller industries. Clearly there has to be a new strategy or technology to make this sustainable option economically viable. Membrane distillation (MD) is a currently trending and rapidly developing unique process that can be used to treat saline wastewater. It can concentrate wastewater until near saturation [24], utilize waste heat [20], is made of polymers and can recover water, which makes it a technology worth investigating, techno-economically.

The objective of this paper is to present a techno-economic analysis to determine if membrane distillation is a conceptually solid as well as an economical fit in the zero liquid discharge scheme of processing. Usually zero liquid discharge employs a brine concentrator (mechanical vapour compression evaporator) [23] to concentrate the wastewater to near saturation with the help of thermal/electrical energy before it can be sent to the final step of the process. Brine concentrators being robust, they are also notorious for being very expensive, usually because of the use of high grade metals and a compressor [23,25,26]. Undoubtedly, the brine concentrator recovers water (60-90\%), but since a majority of them use electrical energy [3] (as opposed to steam driven), for a lower energy consumption, as their main source of energy to drive a compressor, it limits the application where waste energy such as waste heat could be utilized.

Membrane distillation (MD) certainly uses thermal energy but since it functions at not $>85^{\circ} \mathrm{C}$, and is made of polymers it holds great potential to fulfilling conditions of waste heat utilization while being economical. Although attempts on full scale cost analyses to compare MD and brine concentrators have been done before, they have not done enough justice to MD module and system design [25] one of the reasons being that the variant of MD (direct contact membrane distillation) mostly chosen in literature [25] is not always optimal for the application in the manner the research is conducted due to for example its higher sensitivity to the impact of driving force reduction through the impact of salt a topic well discussed by [27] along with other recommendations on selecting the appropriate channel configuration and membrane for different applications. Thus, this work aims at providing a techno-economic answer to whether choosing a ZLD scheme for an industrial wastewater treatment with MD as a component by substituting the brine concentrator is beneficial or not; which implies designing MD modules for such application with a full scale cost analysis for both technologies.

As energy in the form of heat or electricity and water are the most extensively used resources common to a majority of industries, reducing the use of water and energy at the source or, utilizing waste streams of energy such as waste heat in order to recover water would paint a better economic picture for any industry.

\section{Methods}

In order to make the analysis as realistic as possible a module design and subsequently a system design was simulated with a set-up which has been validated through various experimental, bench scale and field tests [28]. Within the module and system design, module types were simulated that are currently producible and have been tested in a lab environment as minimum requirement. Cost calculation methods were applied after the system design and are described in the following sections.

\subsection{Cost calculation methods}

To evaluate the costs and compare all systems, the total costs were divided into capital expenditure (CAPEX) and operating expenditure
Table 1

Description for the distribution of CAPEX costs.

\begin{tabular}{|c|c|c|}
\hline No. & Type of cost & Description \\
\hline 1 & Major process equipment & $\begin{array}{l}\text { Includes major equipment, example MVC unit } \\
\text { or MD modules }\end{array}$ \\
\hline 2 & $\begin{array}{l}\text { Piping and other } \\
\text { equipment }\end{array}$ & $\begin{array}{l}\text { Includes auxiliary equipment such as heat } \\
\text { exchangers, pumps etc. as well as piping } \\
\text { system }\end{array}$ \\
\hline 3 & $\begin{array}{l}\text { Electrical and } \\
\text { instrumentation }\end{array}$ & $\begin{array}{l}\text { Includes all measuring, controlling } \\
\text { instruments, and electrical system }\end{array}$ \\
\hline 4 & Engineering & Costs for performing engineering design \\
\hline 5 & Installation & Costs for installation on site \\
\hline
\end{tabular}

(OPEX) and then analyzed as total costs over fixed plant life times; to facilitate this, a cost calculation sheet was developed in Microsoft Excel. In order to obtain valid CAPEX and OPEX values for comparison, figures were obtained from literature and researched from various vendors and manufacturers of MVC systems. MD costing was conducted based on actual figures and realistically developed degression curves for upscaling. From this data CAPEX, OPEX and return on investment (ROI) values are derived for comparison of MD and MVC for three different capacities of wastewater to be treated per day. The cost figures are given in the currency EUROS.

\subsubsection{Capital expenditure}

The capital costs can be defined as the fixed, onetime expenses that incur through purchase of equipment, or construction, buildings etc. used in the production of goods. This capital or fixed cost $\left(\mathrm{C}_{\mathrm{CAP}}\right)$ can be divided for both the technologies into categories shown in Table 1:

The total (or individual) capital costs will be calculated as an amortized capital expenditure with an assumed practical interest rate as follows:

Amortised CAPEX $=\mathrm{C}_{\mathrm{CAP}}\left[\frac{i(1+i)^{n}}{(1+i)^{n}-1}\right]$

where $i$ is the interest rate and $n$ is the expected plant life in years [29]. In this work, an effective interest rate of $4 \%$ and plant life expectancies of 2, 4, 7 and 20 years are assumed [30]. As real time vendor data is difficult to obtain, some of the sub costs in the list above are assumed as a fraction of the major equipment cost based on references available in literature for the specific systems. The estimation of major process equipment cost is decisive as it represents the major share of the CAPEX; these costs were evaluated/acquired based on literature as well as input from vendors. The capacity method was used to estimate costs wherever specific data for the required capacity was not. It is given by:

$C=C_{\text {ref }}\left(\frac{K}{K_{\text {ref }}}\right)^{m}$

where $C$ and $K$ are the cost and capacity respectively of your equipment; $C_{r e f}$ and $K_{r e f}$ are the reference cost and capacity values from a valid reference data and $m$ is the degression coefficient (also known as cost capacity factor) which is used in order to accommodate the economy of scale. For example, the degression coefficient for a salt water resistant heat exchanger is assumed to be 0,8 and was adopted from [28]. Some reference costs for MVC units, in literature, have been estimated five to ten years ago which requires them to be updated to current year. This has been done by cost indexes (based on the availability of cost index for the latest year); the one used in this paper is the 'chemical engineering plant cost index (CEPCI)'. It is given by:

$C=C_{\text {ref }}\left(\frac{\text { Cost index at present year }}{\text { Cost index when estimated }}\right)$

For cost evaluation of MD modules, the input was based on information provided by SolarSpring GmbH, Freiburg. Cost estimation for MD modules will be discussed in Section 5.1 Capital expenditure 
Table 2

Categories for main OPEX costs types.

\begin{tabular}{|c|c|c|}
\hline No & Type of cost & Description \\
\hline 1 & Thermal energy & $\begin{array}{l}\text { Specific to MD only, includes costs for use of } \\
\text { steam as a heat source }\end{array}$ \\
\hline 2 & Electrical energy & The costs due to use of electrical energy \\
\hline 3 & Chemicals & $\begin{array}{l}\text { Includes costs due to use of various chemicals for } \\
\text { cleaning, dosing etc. }\end{array}$ \\
\hline 4 & Labour & Costs for personnel required to operate the plant \\
\hline 5 & Replacement & $\begin{array}{l}\text { Specific to MD only, includes cost for } \\
\text { replacement of membranes }\end{array}$ \\
\hline 6 & Insurance & $\begin{array}{l}\text { Costs for insurance in case of an unexpected } \\
\text { event }\end{array}$ \\
\hline 7 & $\begin{array}{l}\text { Service and } \\
\text { maintenance }\end{array}$ & Costs for maintenance of plant \\
\hline
\end{tabular}

(CAPEX) calculation for MD.

Auxiliary equipment includes equipment such as pumps, heat exchangers, interconnecting piping, vacuum pumps etc. The heat exchanger costs for MD were calculated according to the capacity method assuming that it is a gasketed plate heat exchanger with titanium as basic material of construction.

\subsubsection{Operating expenditure}

The operating costs (OPEX) are divided into the following sub categories given in Table 2 .

The costs for thermal energy are based on costs of steam available in various literatures. This will be stressed upon in Section 5.2 Operating expenditure (OPEX) for MD. The case of electrical energy is straight forward as countries offer specific unit price if electricity is purchased from the grid, which was assumed in this case. The cost of electric energy might be insignificant in the case of MD but it is the only source of energy for an MVC system as the compressor is its major energy expense without the use of live steam. In MD systems, the feed pump, the vacuum pump and controls are the only consumers of electrical energy and the costs for these have been calculated for a centrifugal and vacuum pump (v-AGMD) based on pressure drops for MD module, heat exchanger and piping losses. Thus, the yearly costs of electricity have been estimated by the following equation

$$
\begin{aligned}
C_{E L E X}= & \dot{q}_{\frac{\text { permeate }}{\text { distillate }}}\left(\frac{\mathrm{m}^{3}}{\text { year }}\right)^{*} \text { unit price of electricity }\left(\frac{€}{\mathrm{kWh}}\right)^{*} \\
& \text { specific electrical energy consumption }\left(\frac{\mathrm{kWh}}{\mathrm{m}^{3}}\right)
\end{aligned}
$$

where $\dot{q}_{\text {permeate/distillate }}$ is the fresh water produced ('permeated' for MD and 'distilled' for MVC) from the respective technology over a period of one year.

Other costs such as service and maintenance, chemicals and insurance will be assumed as a percentage of the major equipment cost as followed in standard literature for high concentration salts. Replacement of membranes is a cost specific to MD and does not apply for the MVC approach.

\section{Fundamentals}

\section{1. $Z L D$}

Conventional ZLD systems (Fig. 1) that are employed today commonly involve a pretreatment stage followed by a RO system. After this pre-concentration the brine is fed to an evaporator in order to produce a concentrate near to its respective saturation limit. This evaporation is often practiced in a brine concentrator which operates on the principle of mechanical vapour compression (MVC). The subsequent crystallization step is usually carried out by a forced circulation crystallizer [23] or an evaporation pond before disposing the solids to a landfill.
The recovery of valuable resources from the solids or highly concentrated brine is a further option. From all three concentration stages, $\mathrm{RO}$, brine concentrator and brine crystallizer the permeate and distillate is recovered and reused.

State of the art RO has proven itself to be a suitable, energy efficient $\left(2-4,5 \mathrm{kWh} \mathrm{el} / \mathrm{m}^{3}[31]\right)$ and cost effective technology, given a certain standard of pretreatment is present. Thus, it is applied as the initial concentration step before the evaporation technologies. RO faces an array of limitations presented in [32] which can be expected to increase with higher salt concentrations e.g. osmotic pressure increase in relation to the feed concentration. Typically, RO is applied in salinity regions $<70.000 \mathrm{ppm}$.

Brine concentrators deal with high amounts of salts and are primarily made out of metals, which makes them vulnerable to corrosion. These corrosion issues make the use of high grade metals necessary such as nickel based alloy or titanium leading to high capital costs. A specific analysis of these costs is given in Section 6 .

The operating costs for these units are also relatively high due to electrical energy consumption. There is enough data published regarding the electrical energy consumption for MVC systems in scientific papers, reports as well as from actual vendors for a zero liquid discharge operation. Thiel et al. [33] reports values from 23 to $42 \mathrm{kWh} / \mathrm{m}^{3}$ of distillate for a single stage MVC system depending on the compressor efficiency and system size. Mcginnis et al. [34] in a pilot study on forward osmosis desalination on high salinity brines has reported values between 28 and $39 \mathrm{kWh} / \mathrm{m}^{3}$ of feed for an MVC desalination system used to treat oil and gas produced water with an inlet concentration between 45.000 and $80.000 \mathrm{mg} / \mathrm{L}$; and approximately $37 \mathrm{kWh} / \mathrm{m}^{3}$ of feed for the same feed with a TDS of $70.000 \mathrm{mg} / \mathrm{L}$. As this value is reported according to the volume of feed, the specific value for energy consumption per volume of distillate produced is higher than the value reported per volume for feed (depending on the recovery). Tong [23] in a study concerning the zero liquid discharge trend on a global scale has reported electrical energy consumption values for ZLD MVC systems at $20-25 \mathrm{kWh} / \mathrm{m}^{3}$ of distillate. J. Gillron [26] has reported energy consumption values of $20-25 \mathrm{kWh} / \mathrm{m}^{3}$ of concentrate for brine concentrators and crystallizers. A brine concentrate treatment and disposal options report [35] prepared by the U.S. department of the interior bureau of reclamation reports energy consumption values of around $19-24 \mathrm{kWh} / \mathrm{m}^{3}$ of feed for a brine concentrator used as a step in ZLD operation. Similarly, Mickley [36] in a report for the WaterReuse Foundation reports energy consumptions of around $25 \mathrm{kWh} / \mathrm{m}^{3}$ of feed. Vendors have also reported several values for energy consumptions, such as from $\mathrm{H} 2 \mathrm{O} \mathrm{GmbH}$ [37], which reports a value as high as $55.4 \mathrm{kWh} / \mathrm{m}^{3}$ of distillate for its VACUDEST system where wastewater is claimed to be reduced to $0.5-5$ times the original volume.

The use of an evaporation pond as a final step can be perceived as simple and cost effective but in reality it is usually used only for lower daily brine flow-rates due to cost drivers such as required land surface and the need of a landfill nearby. In addition, as solar energy is the only source of energy for the ponds, the geographical location has a high impact on the process. Also, since the water is evaporated into the atmosphere, evaporation ponds are not a suitable option for water reuse from the final stage $[23,35]$.

Finally, a forced convection brine crystallizer as the more practical final step before disposal or recovery of the solids is a cost sensitive system with respect to investment and operation costs. For example, the investment cost for a $100 \mathrm{~m}^{3} /$ day forced convection crystallizer system is given at 2.3 mio USD by [36]. The operating costs are higher than those connected to a brine concentrator due to the higher electrical energy consumption ranging between approx. $50-70 \mathrm{kWh} / \mathrm{m}^{3}$ [23]. In conclusion, the crystallization stage should be as small as possible in relation to the whole ZLD chain.

Fig. 2 shows the operating ranges in which the different processes operate within a ZLD scheme in terms of concentration, showing the salinity region which bears the most potential for new technologies. 


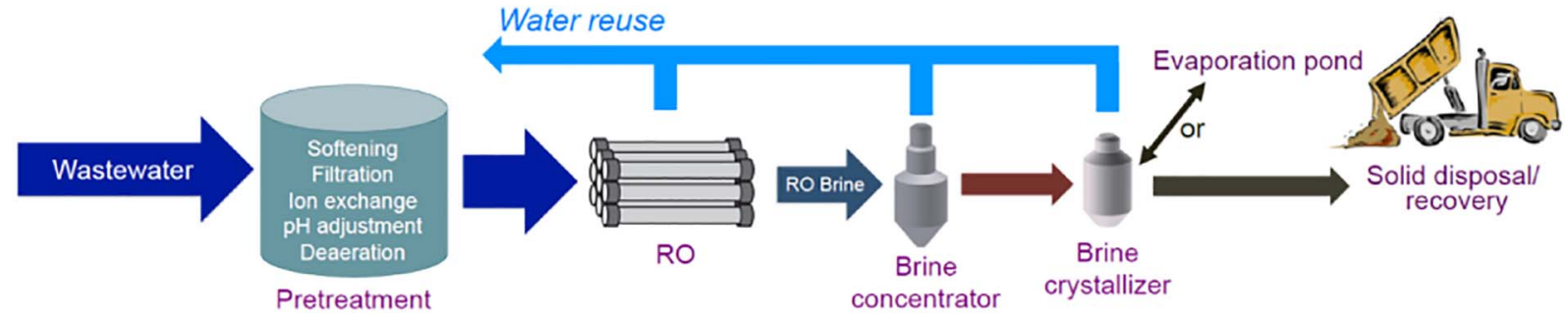

Fig. 1. Schematic for two types of thermal ZLD systems. [Adapted from [23]]

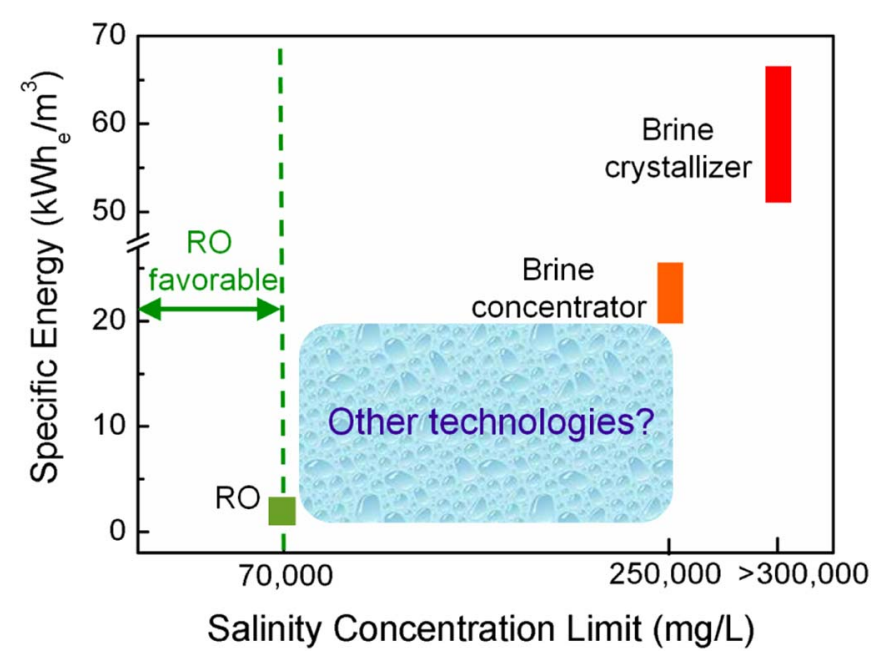

Fig. 2. Operating ranges of salt concentration in a conventional ZLD system with a potential scope for new technologies [23].

\section{2. $M V C$}

Mechanical vapour compression technology is arguably the most extensively used process in any wastewater volume reduction or zero liquid discharge plant around the globe. Also termed as brine concentrators, they consist of an evaporator in which the condensing water vapours on one side of a heat transfer surface liberate latent heat to evaporate distillate from the brine on the other side. A compressor supplies the driving force without the need of an external heat source. As the feed water often consists of seawater or brine and in order to minimize scaling, the temperature of the process is reduced by lowering the overall pressure. When coupled with a crystallizer (amongst other options), a zero liquid discharge operation can be carried out in which the feed is concentrated until near saturation in the brine concentrator and then converted to a solid waste/product in the crystallizer.

The exemplary MVC unit shown in Fig. 3 consists of a shell and tube heat exchanger, on the tube side of which the brine flows as a thin film which is created by the brine distribution system. The fresh brine (1) is received in the brine sump (2). The sump is operated under a negative pressure generated by the compressor (4). The compressor also compresses the generated vapours sucked from the brine section and raises the pressure and temperature and thereby the enthalpy of the vapours (5) which condense on the walls of the tube in the falling film evaporator (3). The circulating brine (7) on the other hand receives the latent heat from the condensing vapours and is partially evaporated. The condensed distillate (6) is in turn used to pre heat the fresh brine (1).

As aforementioned, brine concentrators can concentrate highly saline feed solutions up to near saturation, but then must be made of titanium or nickel based alloy. The vendors contacted during the research for this work recommended a combination of Hastelloy $\mathrm{C}$ and titanium components. The pre-heating heat exchanger should also

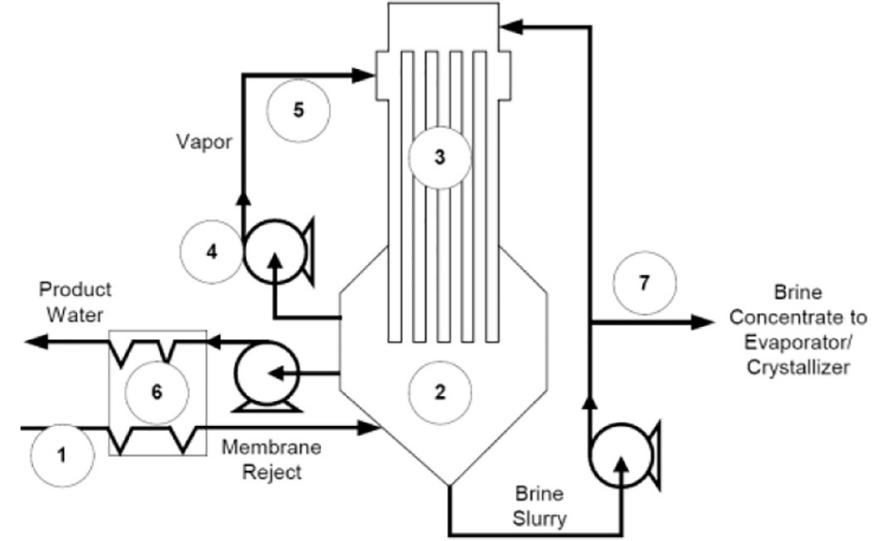

Fig. 3. Typical scheme of a MVC brine concentrator [35].

consist of titanium tubes. MVC has proven to be a reliable and robust technology over the past 30 years can operate with few complications.

\section{3. $M D$}

Membrane distillation (MD) is a fast developing and current trending technology initially proposed by Bodell to convert "impotable aqueous fluids into potable water", especially for saline water [5]. It is a membrane based but thermally driven separation process which allows the passage of vapour through a hydrophobic, highly porous membrane by virtue of a vapour pressure difference which is generally caused by a temperature difference existing on both sides of the membrane [28], Although most of the current research on MD is based on desalination of saline water or seawater $[28,38,39]$, MD has a great potential yet to be explored $[1,40,41,42,43]$ on a large commercial scale for the treatment of various corrosive and/or fouling industrial effluents as well as brine treatment with zero liquid discharge where current established practices might falter due to the increasing governmental regulations [23].

The mass transfer occurring in membrane distillation can be stated as a combination of molecular and Knudsen diffusive transport. Since the membrane is actively involved at the center of the whole process, the transport of vapour across the complex pore structure of the membrane should be considered while describing the effective mass transfer. Heat and mass transfer fundamental equations used in the simulation model can be observed in Winter [28] and will therefore not be listed in detail here.

As there are different ways to establish the thermal driving force across a membrane several different channel configurations have been developed in membrane distillation. Fig. 4 displays two different channel configurations on which the further thermodynamic and economic analyses in this work are based. The left variant, direct contact membrane distillation (DCMD) [44] relies only on a membrane for the division of the hot feed channel and the cooler permeate side. It is the most widely studied and simplest version of MD. Osmotic membrane distillation [45] and other membrane contactor processes can also be achieved with this channel set up. Even though the DCMD variant 

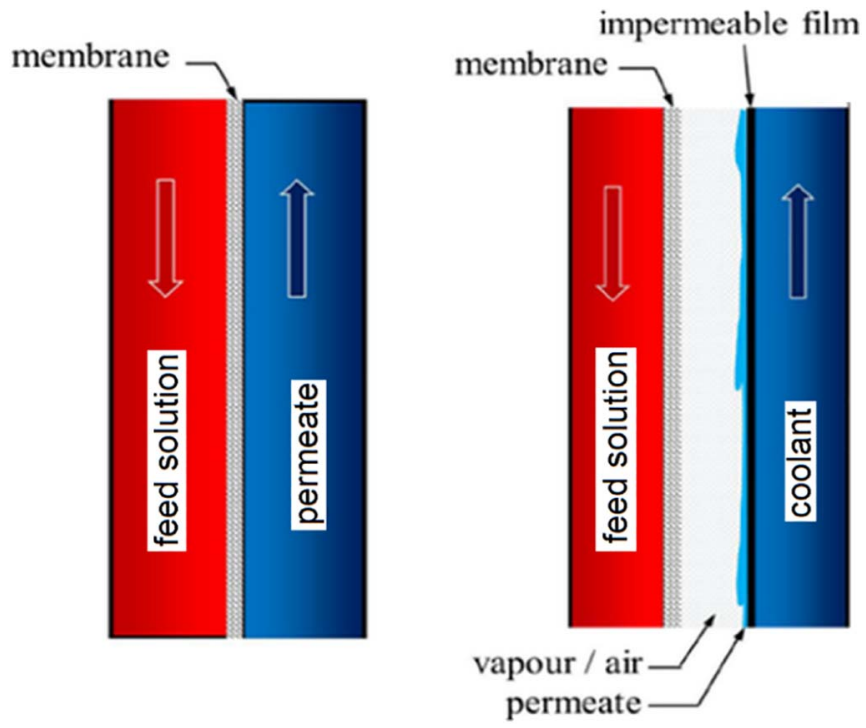

Fig. 4. DCMD and AGMD channel configuration variants (from left to right).

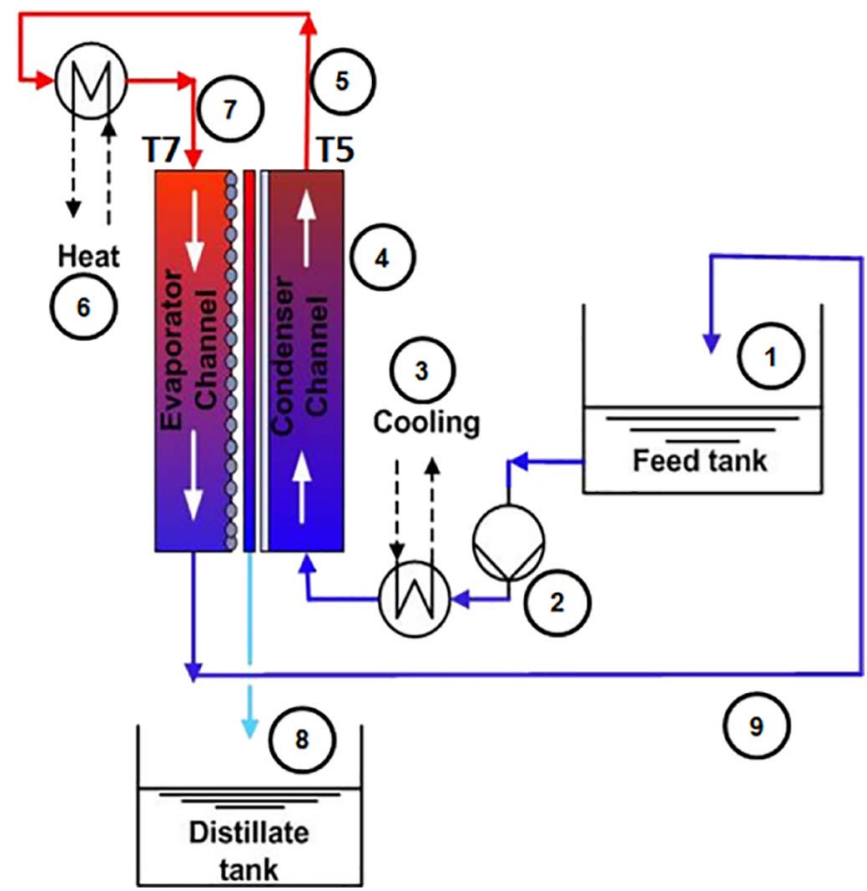

Fig. 5. Scheme of a batch type MD system.

shows a low overall heat and mass transfer resistance which enables higher fluxes it comes with the tradeoff of a higher conductive heat transfer which decreases the thermal efficiency of the process. The right channel configuration in Fig. 4 is named air gap membrane distillation (AGMD) [46]. The main difference in comparison to DCMD is the separation of the coolant from the permeate by an impermeable film. This enables the use of any liquid as coolant e.g. the feed solution and thus has an advantage over DCMD regarding the recovery of heat inside the MD module. While thermal insulation is strongly increased by the air gap, which is wider than the membrane itself, the mass transfer resistance is increased alongside giving a lower flux but also lower conductive heat transfer across the combined membrane and gap with condenser film. The produced distillate trickles to the bottom of the module and exits the outlet driven by gravity. One way to reduce the diffusive mass transfer resistance caused by air in the gap, is by applying vacuum to the gap. This variant is named vacuum air gap membrane distillation (v-AGMD) [47]. Unlike in vacuum membrane distillation (VMD) [48] this vacuum does not contribute to the driving force which remains to be of thermal nature [28], but simply lowers diffusion resistances. Fig. 5 shows a basic Air Gap MD scheme with a feed tank (1) and a distillate tank (8) in a batch mode. After exiting the feed tank (1) and being pumped (2) through the cooling heat exchanger (3) the feed enters the condenser inlet of the module(s) (4) exiting the condenser outlet (5) preheated by the evaporator channel running in counter current. The required temperature difference is supplied through the heating heat exchanger (6) after which the feed enters the evaporator inlet (7). The produced vapour condenses in the distillate channel and is collected in a distillate tank (8). The remaining brine (9) is recirculated to the feed tank (1). A continuous or semi batch mode is also possible.

MD-related key performance indicators will be introduced in the following equations and will be used for the discussion of the system design and cost comparison.

Module or system output is defined as the mass of distillate produced per hour:

$\dot{m}_{d}\left[\frac{\mathrm{kg}}{\mathrm{h}}\right]$

Transmembrane flux is the rate of distillate throughput per $\mathrm{m}^{2}$ of membrane:

$j_{d}\left[\frac{\mathrm{kg}}{\mathrm{m}^{2} \mathrm{~h}}\right]$

In order to evaluate energy consumption and internal heat recovery, the terms gained output ratio (GOR) and specific energy consumption (thermal and electrical) are introduced:

GOR $=\frac{\dot{m}_{d}^{*} \Delta h_{v}}{\dot{m}_{f}^{*} c_{p}^{*}\left(T_{7}-T_{5}\right)}[-]$

$\Delta h v$ represents the specific evaporation enthalpy in $\mathrm{kJ} / \mathrm{kg}$ and is multiplied with the amount of distillate produced in order to determine the energy used for the corresponding output. $c_{p}$ represents the specific heat capacity. Temperatures T5 and T7 are indicated in Fig. 5. GOR gives a relation of total energy used for distillation and the energy actually entering into the system. The rest of the energy required is recovered internally. A GOR of $1\left(\sim 655 \mathrm{kWh} / \mathrm{m}^{3}\right)$, is the equivalent of the energy required for direct evaporation without heat recovery.

Specific thermal energy consumption $S E C_{t h}$ is given as:

$S E C_{t h}=\frac{\dot{m}_{f}^{*} c_{p}^{*}\left(T_{7}-T_{5}\right)}{\dot{m}_{d} / \rho}\left[\frac{\mathrm{kWh}}{\mathrm{m}^{3}}\right]$

Showing the amount of thermal energy needed for a certain mass flow of distillate and $S E C_{e l}$

$S E C_{e l}=\frac{P_{e l}}{\dot{m}_{d / \rho}}\left[\frac{\mathrm{kWh}}{\mathrm{m}^{3}}\right]$

is the definition of specific electricity consumption. Real values will be calculated and used for the economic comparison.

\section{MD system design}

\subsection{Assumptions and boundary conditions}

For the subsequent system design, a membrane distillation unit will be assumed to operate until a TDS of $250.000 \mathrm{ppm}$ to further concentrate a RO brine with a TDS of $70.000 \mathrm{ppm}$. The softening step prior to $\mathrm{RO}$ is assumed to remove the hardness in the brine. Fig. 6 proposes a ZLD system with an integrated membrane distillation stage.

The target design capacities of wastewater to be treated were chosen in order to represent small, medium as well as large capacities. Based on range of standard models offering wastewater ZLD solutions from 


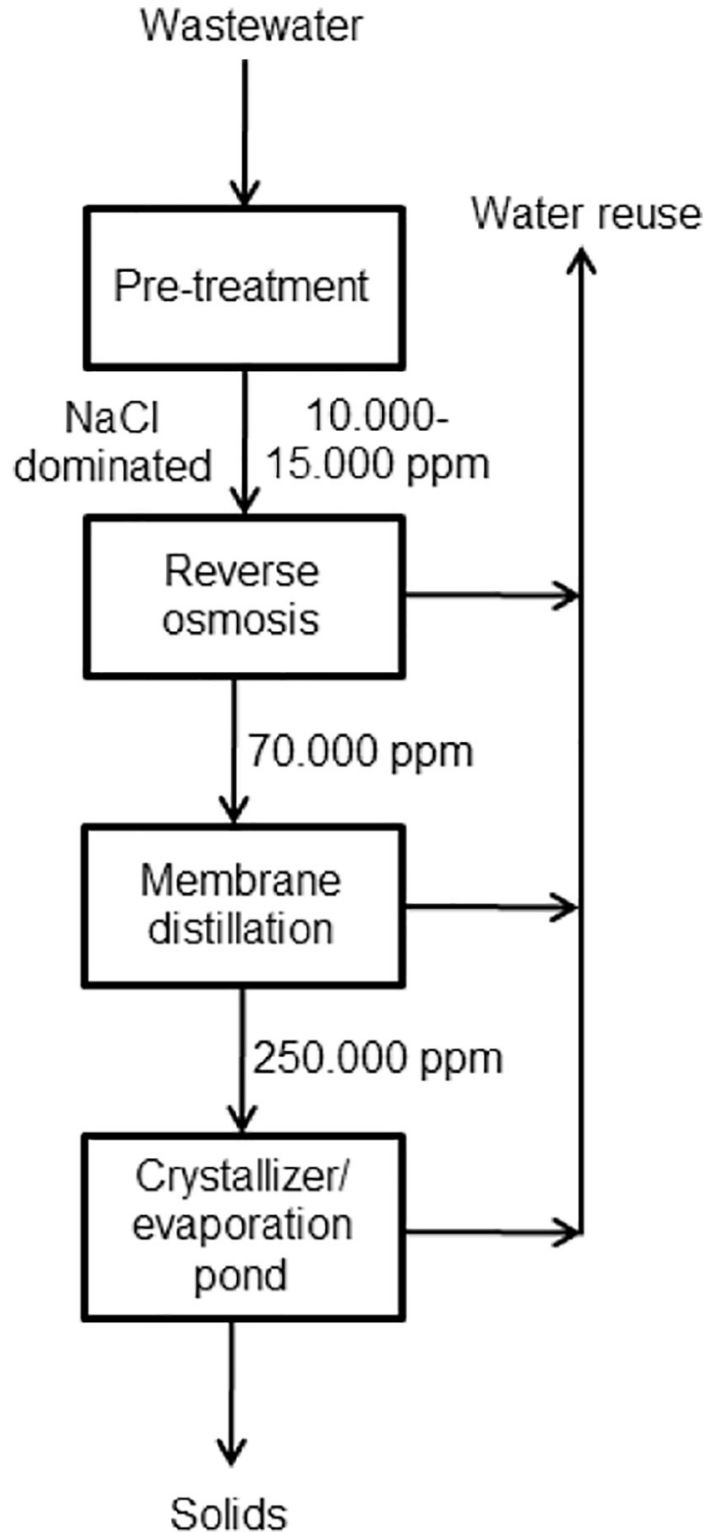

Fig. 6. Scheme for ZLD with MD.

various leading vendors $[37,49]$ the treatment capacities have been assumed to be as follows:
1. $10 \mathrm{~m}^{3} / \mathrm{d}$
2. $100 \mathrm{~m}^{3} / \mathrm{d}$
3. $1000 \mathrm{~m}^{3} / \mathrm{d}$

The next step towards a comparative cost analysis, after setting the aforementioned boundary conditions regarding capacity and TDS, is the MD module design. The simulative design and optimization of MD modules will form the basis for the cost analysis, as it directly affects all relevant costs. Module optimization while designing MD modules is always a trade-off between capital costs and operating costs. This section will discuss parameters which influence this trade off; and the best operating point will be selected as an ideal module for cost analysis within the selected TDS range. The design is performed based on simulation results from the MD model developed at Fraunhofer ISE in Freiburg. This model has been validated through a number of lab and field trials [28] for seawater desalination as well as for water with high salt concentration.

It can be assumed that there is no significant difference between a

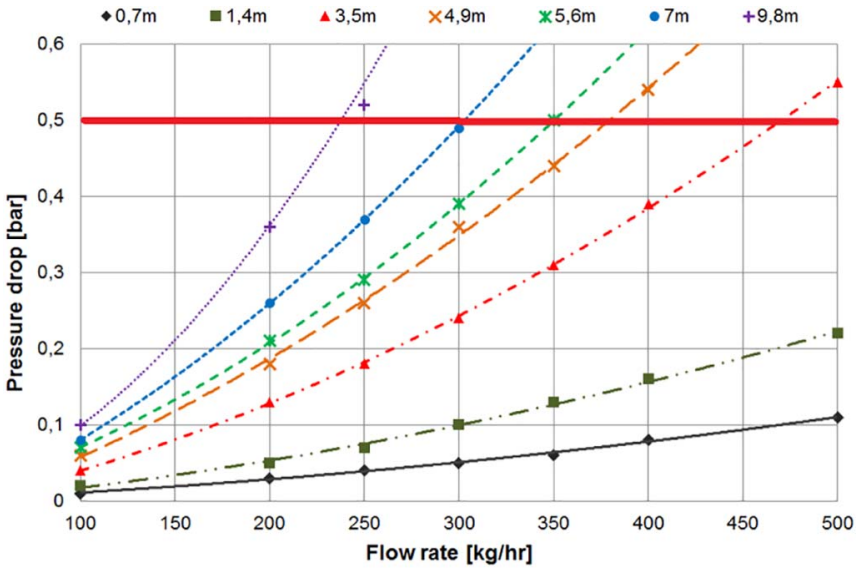

Fig. 7. Pressure drop as a variation of feed flow for a single module with respect to different channel lengths at an inlet feed salinity of $240.000 \mathrm{ppm} \mathrm{NaCl}$.

spiral wound and a plate and frame module in pressure drop and performance, given that channel geometry and operational parameters are identical. The heat transfer and pressure loss is dominated by the spacer [50] and channel configuration rather than the type of construction. However, a plate and frame type is selected for this work for reasons of cost relevant advantages regarding membrane replacement.

The following points give a guideline for the order of decision making regarding the MD system design and are applicable to all channel configuration.

1. Analysis of pressure drop for different channel lengths and feed mass flows (Fig. 7)

2. Analysis of output and GOR for different channel lengths and feed mass flows at starting and end point of the proposed MD batch operation range (Figs. 8, 9)

3. Comparison of output, GOR and transmembrane flux for DCMD, AGMD, v-AGMD at a selected feed mass flow and for different channel lengths (Figs. 10, 11)

4. Analysis of output, GOR and transmembrane flux for the batch process (Fig. 12)

5. Cost analysis of the selected module and system design (Section 5 Cost analysis for membrane distillation systems). After cost analysis, the selection of optimal channel length is affirmed by comparing the amortized capital, operating and total costs for various channel length modules (Section 5.4 Affirmation of channel length selection)

The constant and variable data for each simulation which was either gathered from literature [28] or from the SolarSpring GmbH database, is given in Table 3.

\subsection{Flow rate and pressure drop}

The first simulations carried out address the analysis of pressure drop at different feed flow rates for different channel lengths. Membrane distillation is an ambient pressure process and the maximum pressure that can be present in the flow channels is limited by the materials inside the MD modules as well as the liquid entry pressure which is a membrane specific property [51].

Although liquid entry pressures are commonly $\sim 3.5$ bar(g) allowing for a good margin before wetting commences, tearing of the membrane has been observed at much lower pressures of about 1-2 bar(g) [52] due to the differential pressure experienced by the membrane. Membrane degradation during operation also makes it necessary to apply a safety factor. Due to this phenomenon and the fact that there is only one major pump in the whole system, the system pressure drop becomes a limiting factor in system design. With increasing salt concentration, the 

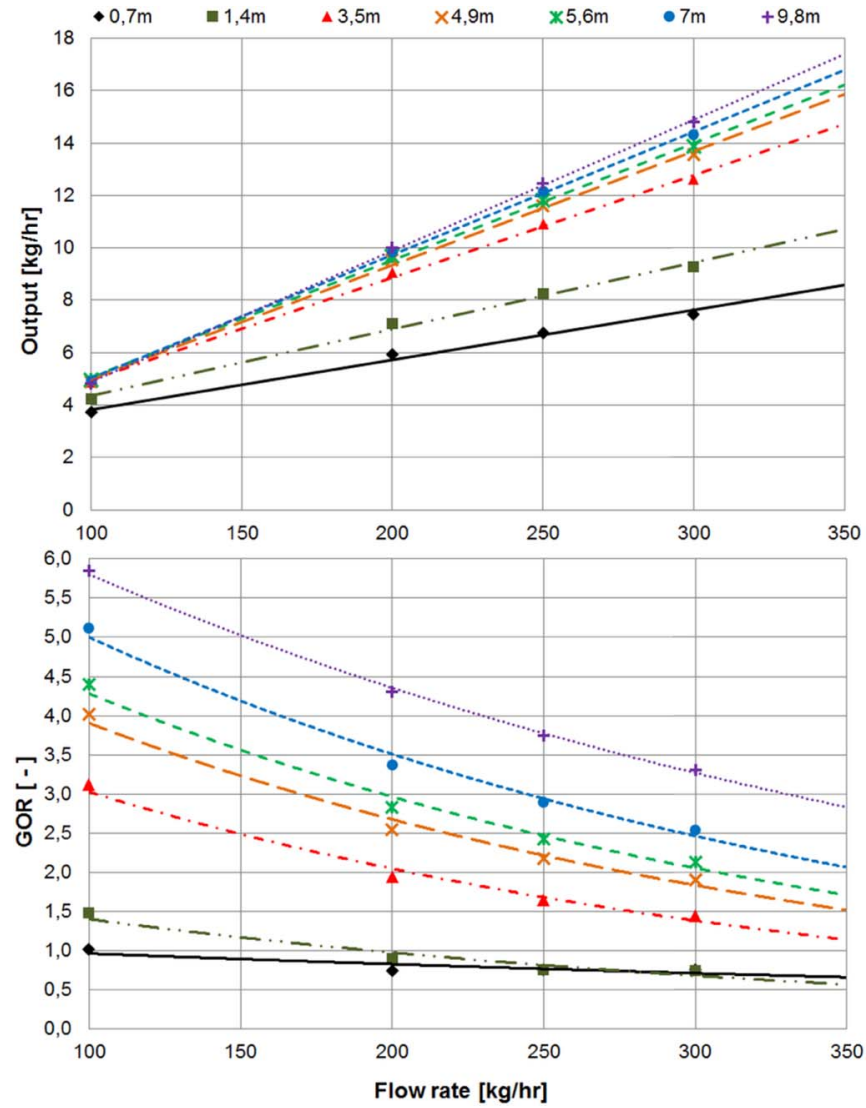

Fig. 8. Output and GOR for different channel lengths over varied feed flow rates in an AGMD module; $\mathrm{T}_{\mathrm{ei}}=80^{\circ} \mathrm{C}, \mathrm{T}_{\mathrm{ci}}=25^{\circ} \mathrm{C}$, inlet feed salinity $70.000 \mathrm{ppm} \mathrm{NaCl}$.

density and viscosity also increases causing a higher pressure drop in the piping as well as the primary heat exchanger responsible for heating the feed. Thus, if the inlet pressure should be $<1$ bar(g), there exists only a small margin for pressure drop in the MD module. Assuming a pressure drop of 0,3 bar for the heat exchanger and 0,1 bar as piping losses including static head (for the highest concentration of inlet salinity in feed), to satisfy a $1 \mathrm{bar}(\mathrm{g})$ inlet criteria and including a safety margin of $0,1 \mathrm{bar}$, the maximum pressure drop that is permitted in an MD module is restricted to $<0.5$ bar. Thus, simulations were performed for different flow rates in a once through MD module to test the pressure drop at the boundary conditions defined in the previous section for the highest feed salinity in the module with $240.000 \mathrm{ppm}$. Regarding the pressure drop calculations, the following assumptions are made:

- Channel configuration (AGMD, v-AGMD, DCMD) of the module has no dependence on the pressure drop;

- The channel width and spacer is the same for all configurations

- Interdependencies between the channels inside the modules are similar

Table 4 gives the corresponding membrane areas per module for the considered channel lengths. The area values were calculated due to the fixed channel height of $0,7 \mathrm{~m}$ and with 2 active sides.

Fig. 7 shows the end of batch case with an inlet feed salinity of $240.000 \mathrm{ppm}$, flow rates being varied from 100 to $500 \mathrm{~kg} / \mathrm{h}$. Pressure drop varies from as low as $0,11 \mathrm{bar}$ at $500 \mathrm{~kg} / \mathrm{h}$ for a $0,7 \mathrm{~m}$ channel length module to as high as 0,55 bar at $250 \mathrm{~kg} /$ hour feed flow rate for a $9,8 \mathrm{~m}$ channel. A flow of $300 \mathrm{~kg} / \mathrm{h}$ for a $7 \mathrm{~m}$ channel length stays just below the 0.5 bar mark satisfying the criteria. All lengths below $7 \mathrm{~m}$ seem to comply with the pressure drop for a flow rate of $300 \mathrm{~kg} / \mathrm{h}$ but the $9,8 \mathrm{~m}$ length limits the feasible feed flow rate to $\sim 240 \mathrm{~kg} / \mathrm{h}$.
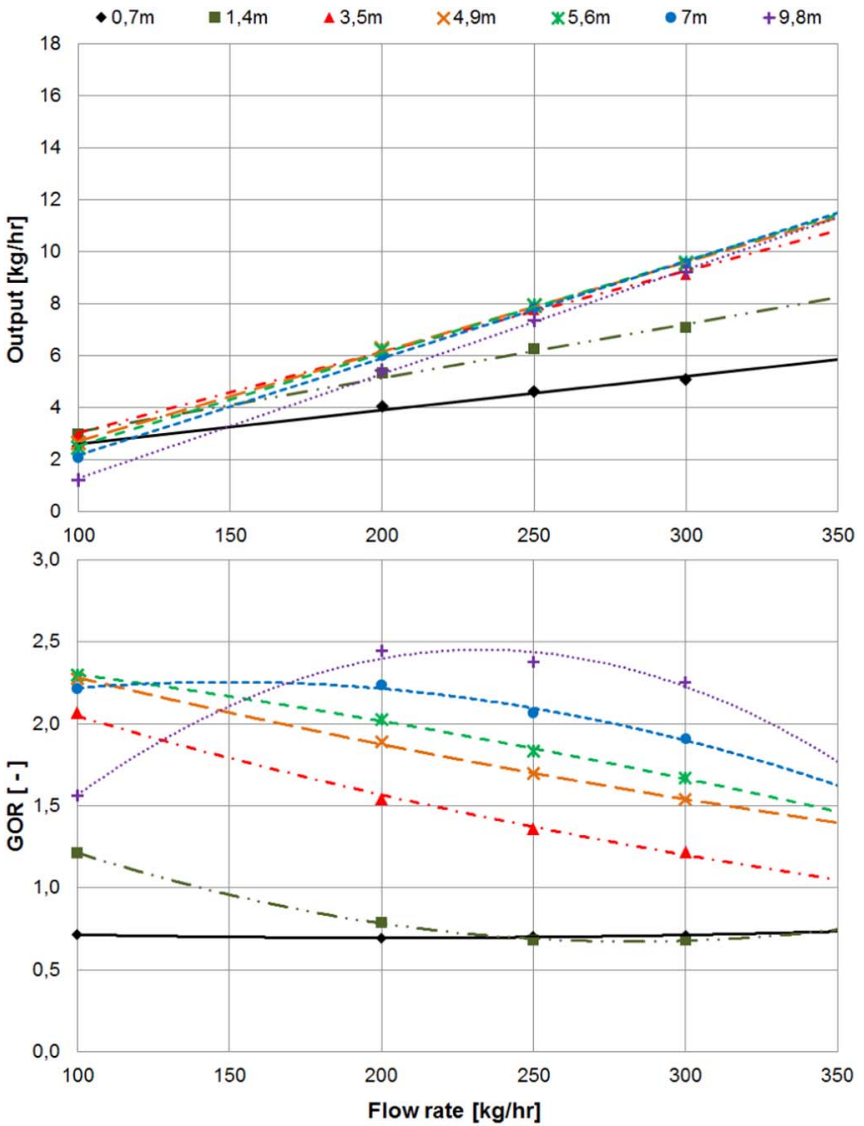

Fig. 9. Output and GOR for different channel lengths over varied feed flow rates in an AGMD module; $\mathrm{T}_{\mathrm{ei}}=80^{\circ} \mathrm{C}, \mathrm{T}_{\mathrm{ci}}=25^{\circ} \mathrm{C}$, inlet feed salinity $240.000 \mathrm{ppm} \mathrm{NaCl}$.

The calculated deviation between the pressure drop values at $240.000 \mathrm{ppm}$ and $70.000 \mathrm{ppm}$ is between $9 \%$ for a $0,7 \mathrm{~m}$ channel length and $22 \%$ for a $9,8 \mathrm{~m}$ channel length. Since the end concentration viscosity causes the most severe pressure drop, the flow rate of $250 \mathrm{~kg}$ / $\mathrm{h}$ is selected as design feed flow rate for the subsequent economic analysis.

\subsection{Output and GOR consumption at different feed flow rates}

The following calculations address the impact of feed flow rate on module output mass flow and GOR for different channel lengths. Figs. 8 and 9 depict the change in output and energy consumption per single module for different lengths as a function of flow rate. In Fig. 8, $70.000 \mathrm{ppm} \mathrm{NaCl}$ was set as inlet feed salinity and $240.000 \mathrm{ppm}$ was used in Fig. 9. Similar studies for a fixed channel length and varied salinities can be found with [53].

In Fig. 8, an almost proportional influence of feed flow rate on module output is observed. With sufficient channel length $10 \mathrm{~kg} / \mathrm{h}$ are produced at a flow rate of $200 \mathrm{~kg} / \mathrm{h}$. Similar total output is achieved for different channel lengths above $\sim 4 \mathrm{~m}$, showing that the lower availability of transfer surface is compensated by higher driving force established with shorter flow channels. The $7 \mathrm{~m}$ channel produces $14,3 \mathrm{~kg} / \mathrm{h}$ of distillate at $300 \mathrm{~kg} /$ hour feed flow rate and $9,8 \mathrm{~kg} / \mathrm{h}$ at $200 \mathrm{~kg} /$ hour feed flow. The corresponding values for GOR show the effect of internal heat recovery due to channel length variations in the lower graph of Fig. 8. Where the 9,8 and $7 \mathrm{~m}$ channel modules show GOR values of between 2 and 6 respectively, the values for the $0,7 \mathrm{~m}$ channel only exceed a GOR of 1 at $100 \mathrm{~kg} / \mathrm{h}$ of feed flow rate.

The trends in Fig. 9 regarding output for a feed salinity of $240.000 \mathrm{ppm}$ are similar but more pronounced. Due to the loss of driving force through vapour pressure reduction caused by the 

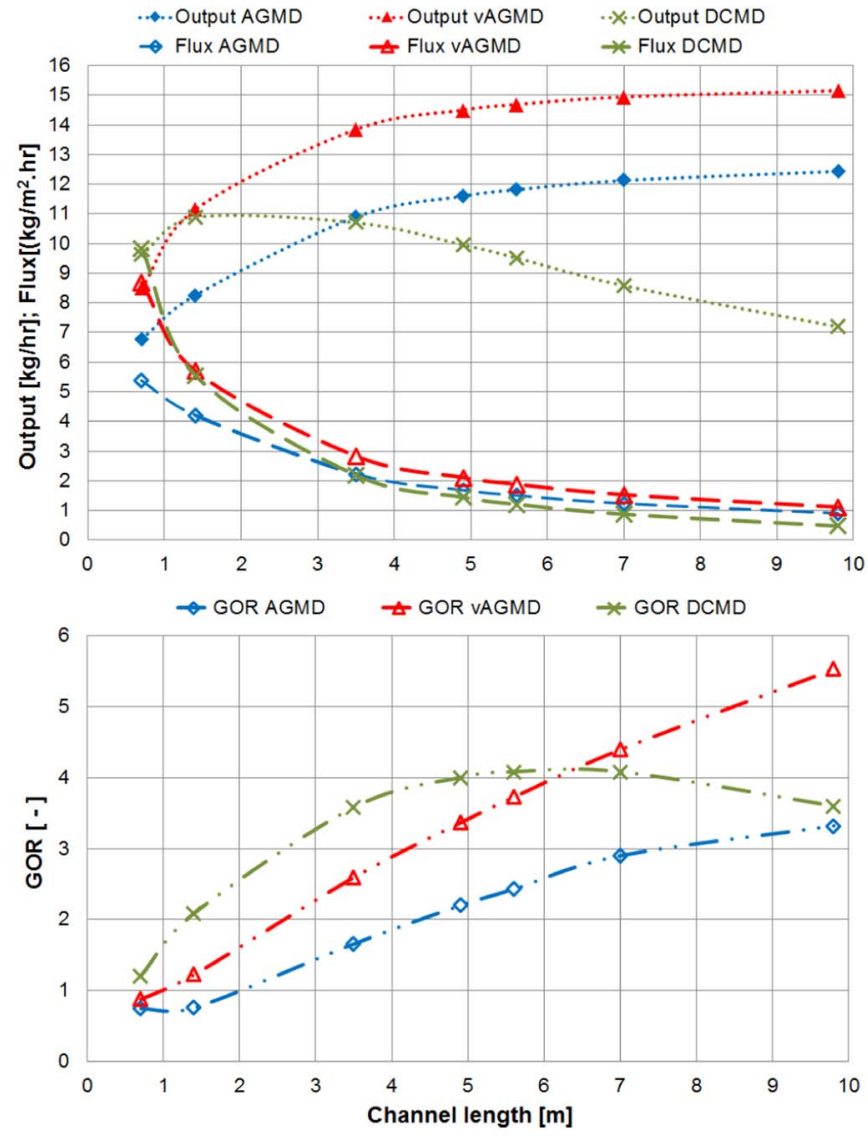

Fig. 10. Output, flux and GOR for DCMD, AGMD and v-AGMD modules of different channel lengths; Feed flow rate $=250 \mathrm{~kg} / \mathrm{h}, \mathrm{T}_{\mathrm{ei}}=80^{\circ} \mathrm{C}, \mathrm{T}_{\mathrm{ci}}=25^{\circ} \mathrm{C}, 70.000 \mathrm{ppm} \mathrm{NaCl}$.

additional dissolved ions in the feed solution, the distillate output curves for all channel lengths above $1,4 \mathrm{~m}$ are very close together at approx. $9,5 \mathrm{~kg} / \mathrm{h}$ for a feed flow of $300 \mathrm{~kg} / \mathrm{h}$ and $6 \mathrm{~kg} / \mathrm{h}$ at $200 \mathrm{~kg} / \mathrm{h}$ as the relative impact of salt increases for lower driving force temperature differences e.g. in a longer channel [53].

Thus, in spite of having similar outputs, due to conduction there is an increase in the outlet condenser temperature leading to a lower heat to be supplied by the primary heat exchanger and thereby increasing the GOR. Lower energy demand denotes lower operating cost e.g. for example in the form of steam. However, a higher length corresponds with higher capital cost in the form of more membrane.

In the lower graph of Fig. 9, GOR values are shown. Overall the GOR values at $240.000 \mathrm{ppm}$ are, as expected, much lower than in the preceding graph as a much higher driving force is needed to evaporate the feed at this salinity. Also, the progression of the curves differ, especially for the 9,8 m channel length, which can be explained as follows: For a certain mean temperature level, the total partial pressure reduction due to salt is independent of the total temperature difference, thus total driving force. Therefore, the relative impact of salt on the driving force becomes more significant for the lower temperature differences at lower feed flow rates [53]. This explains the lower GOR values at $100 \mathrm{~kg} / \mathrm{h}$ in the $7 \mathrm{~m}$ and $9,8 \mathrm{~m}$ channel compared to the values at $200 \mathrm{~kg} / \mathrm{h}$ at this higher salinity level.

Within both graphs, the GOR progression for the $0,7 \mathrm{~m}$ channel length shows hardly any change with increased feed mass flow rate. In such a short channel, no significant heat recovery exists. Thus, the increase in heat supplied to the system for evaporation and the product output are linked in a nearly proportional manner. GOR as a fraction of the two performance indicators therefore remains uniform.

With regard to the initial pressure drop analysis in Fig. 7, the conclusion of this section is the selection of a nominal feed flow rate of
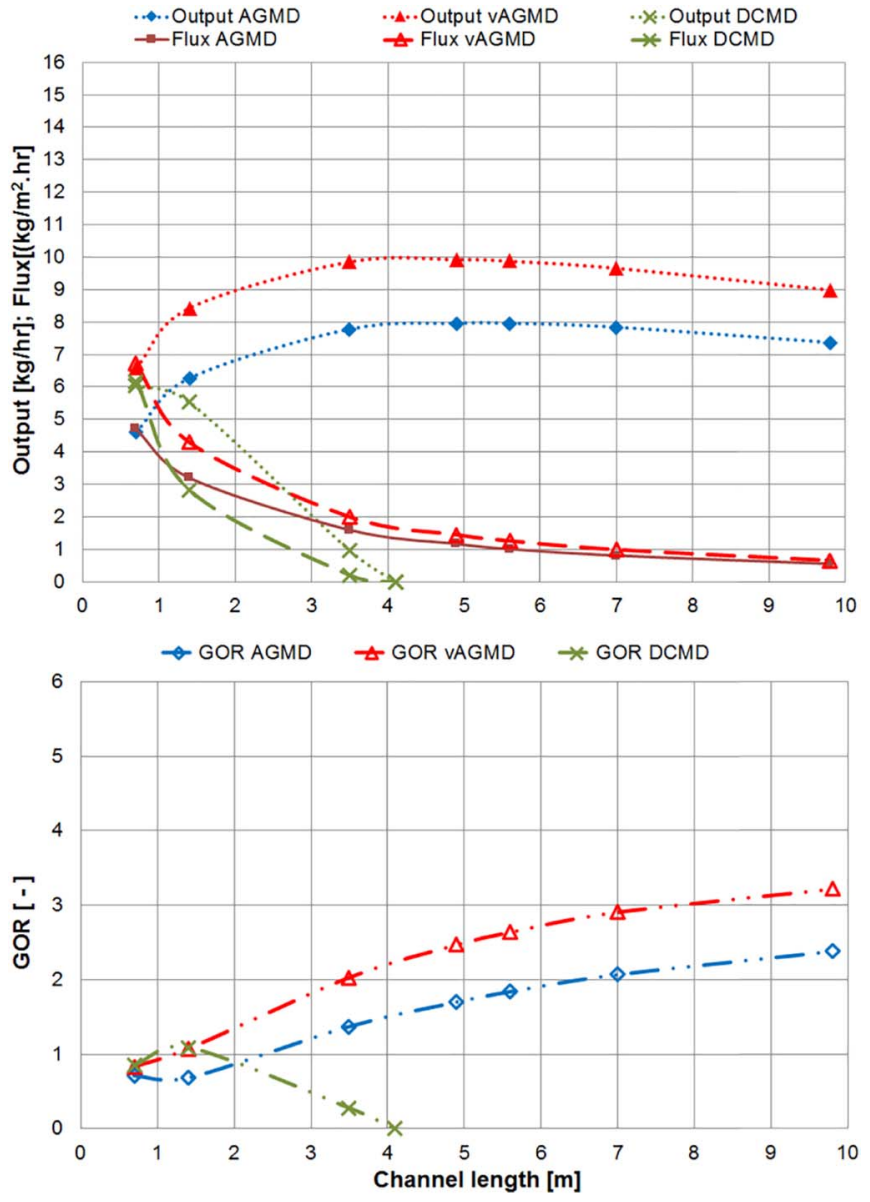

Fig. 11. Output, Flux and GOR for DCMD, AGMD and v-AGMD modules of different channel lengths; Feed flow rate $=250 \mathrm{~kg} / \mathrm{h}, \mathrm{T}_{\mathrm{ei}}=80^{\circ} \mathrm{C}, \mathrm{T}_{\mathrm{ci}}=25^{\circ} \mathrm{C}$, inlet feed salinity 240.000 ppm NaCl.

$250 \mathrm{~kg} / \mathrm{h}$ for the subsequent economic analysis. The basic impact of the start and end salinity level within the proposed batch process (70.000-250.000 ppm) for different feed flow rates and an AGMD channel variant were given in Figs. 8 and 9, showing the suitability of an AGMD set up in principle and the possibilities and effects of varying channel length and feed flow rate within certain boundaries.

\subsection{Output, GOR and flux for different channel configurations and lengths}

In Figs. 10 and 11 output, flux and GOR are varied over channel length for the three channel configurations DCMD, AGMD and v-AGMD. AGMD and v-AGMD values are calculated to generate input for the economic evaluation and DCMD is included for performance comparison due to the frequent use of this channel configuration in literature $[54,55]$. A further aim of the calculations is the determination of a set channel length for the cost analysis. In addition to the key performance indicators introduced in Figs. 8 and 9, GOR (Eq. (3)) and transmembrane flux (Eq. (2)) are presented in Figs. 10 and 11. These values were compared for the three channel variants with different lengths in order to optimize the length of a single module for application in zero liquid discharge. The simulations were performed only for the two boundary inlet feed concentrations of start point (with feed salinity equal to $70.000 \mathrm{ppm}$ ) and the assumed last point (feed salinity equal to $240.000 \mathrm{ppm}$ ) after which the prescribed concentration value (of $250.000 \mathrm{ppm}$ salinity) is reached. The upper graph of Fig. 10 (70.000 ppm) shows the development of output and flux with increasing channel length.

The nature of the curves for AGMD and v-AGMD are very similar, 

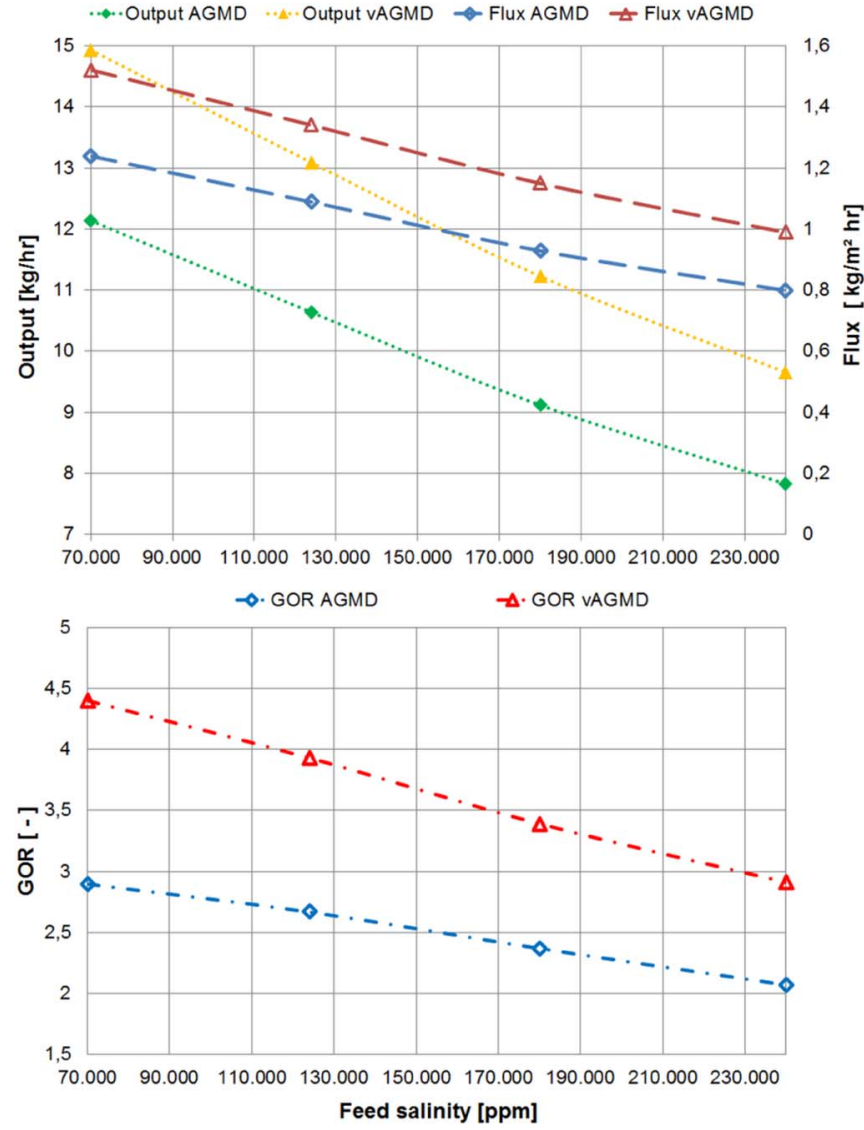

Fig. 12. Output, flux and GOR for AGMD and v-AGMD channel modules and the salinity range within the proposed batch process for ZLD; feed flow rate $=250 \mathrm{~kg} / \mathrm{h}, \mathrm{T}_{\mathrm{ei}}=80^{\circ} \mathrm{C}$, $\mathrm{T}_{\mathrm{ci}}=25^{\circ} \mathrm{C}$.

Table 3

List of variable/constant parameter values for MD simulation.

\begin{tabular}{|c|c|c|c|c|}
\hline No & Parameter & Symbol & Value/range & Unit \\
\hline 1 & Inlet evaporator temperature & $\mathrm{T}_{\mathrm{ei}}$ & 80 & ${ }^{\circ} \mathrm{C}$ \\
\hline 2 & Inlet condenser temperature & $\mathrm{T}_{\mathrm{ci}}$ & 25 & ${ }^{\circ} \mathrm{C}$ \\
\hline 3 & Feed flow rate & $\dot{m}_{f}$ & From 100 to 500 & $\mathrm{~kg} / \mathrm{h}$ \\
\hline 4 & Membrane thickness & $\delta_{\mathrm{M}}$ & 70 & $\mu \mathrm{m}$ \\
\hline 5 & Backing thickness & $\delta_{\mathrm{B}}$ & 280 & $\mu \mathrm{m}$ \\
\hline 6 & $\begin{array}{l}\text { Channel width for condenser } \\
\text { and evaporator (spacer } \\
\text { thickness) }\end{array}$ & $\delta_{\mathrm{C} / \mathrm{E}}$ & 2 & $\mathrm{~mm}$ \\
\hline 7 & Air gap width & $\delta_{\mathrm{AG}}$ & 2 & $\mathrm{~mm}$ \\
\hline 8 & Nominal pore diameter & $\mathrm{d}_{\mathrm{M}}$ & 0,2 & $\mu \mathrm{m}$ \\
\hline 9 & Porosity of membrane & $\varepsilon_{\mathrm{M}}$ & 0,8 & - \\
\hline 10 & Porosity of backing & $\varepsilon_{\mathrm{B}}$ & 0,5 & - \\
\hline 11 & $\begin{array}{l}\text { Porosity of spacer, diamond } \\
\text { structure, flow attack angle } \\
\Theta=70^{\circ}\end{array}$ & $\varepsilon_{s}$ & 0,8 & - \\
\hline 12 & Vacuum pressure for v-AGMD & $\mathrm{P}_{\mathrm{vp}}$ & 0,5 & bar(a) \\
\hline 13 & Fixed channel height of module & $\mathrm{h}$ & 0,7 & $\mathrm{~m}$ \\
\hline 14 & Salinity range for feed & $\mathrm{S}$ & $70.000-240.000$ & $\begin{array}{l}\mathrm{ppm} \\
\mathrm{NaCl}\end{array}$ \\
\hline 15 & Channel length range & $\mathrm{L}$ & From 0,7 to 9,8 & $\mathrm{~m}$ \\
\hline 16 & Configurations & - & $\begin{array}{l}\text { DCMD, AGMD, v- } \\
\text { AGMD }\end{array}$ & - \\
\hline
\end{tabular}

but a certain offset is observed. This offset of higher output and lower energy consumption for $\mathrm{v}$-AGMD is the result of the lower molecular diffusion resistance in this process variant caused by the evacuation of the air gap channel. Starting at an output of $6,7 \mathrm{~kg} / \mathrm{h}$ and $8,5 \mathrm{~kg} / \mathrm{h}$ for the $0,7 \mathrm{~m}$ channel length, both channel configurations appear to converge to a final output level of about $\sim 12,1 \mathrm{~kg} / \mathrm{h}$ for AGMD and
Table 4

Channel length and corresponding membrane area per module.

\begin{tabular}{ll}
\hline Channel length, L $[\mathrm{m}]$ & Membrane area, A $\left[\mathrm{m}^{2}\right]$ \\
\hline 0,7 & 0,98 \\
1,4 & 1,96 \\
3,5 & 4,9 \\
4,9 & 6,86 \\
5,6 & 7,84 \\
7 & 9,8 \\
9,8 & 13,72
\end{tabular}

$14,9 \mathrm{~kg} / \mathrm{h}$ for v-AGMD at a channel length of $7 \mathrm{~m}$. As expected, the GOR is increased due to the better heat recovery in the longer channel module which is indicated by the progression of the values in the lower part of Fig. 10. Even though the output does not increase significantly after a channel length of $7 \mathrm{~m}$, the GOR values do further increase due to the better internal heat recovery in the longer channels.

Analyzing the progression of the DCMD values, a different behaviour can be observed in the output curve. After a short initial increase, the output values begin to decrease above a channel length of $\sim 2.5 \mathrm{~m}$. As explained in conjunction with the values for the $9,8 \mathrm{~m}$ channel length AGMD module, this is due to the lower absolute driving force temperature difference and the impact of vapour pressure reduction through salinity. The reason why only the DCMD curve shows the outcome of this influence at $70.000 \mathrm{ppm}$ is the higher sensitivity of this channel variant to salt in the feed solution when using an identical membrane with respect to material and geometrical properties (e.g. thickness) as in the AGMD variants. As the thermal isolation effect towards sensible heat transfer of only a membrane layer in DCMD in opposition to a membrane layer, a condenser foil and an air gap in the air gap channel variants is much lower, the actual interfacial temperature difference is also smaller and the loss in effective driving force due to the impact of salt on the vapour pressure curve is relatively higher. Using a relatively thicker membrane in a DCMD module can create a similar isolation effect as a foil and gap variant.

The different sensitivity towards the impact of saline concentration can be perceived in the more moderate reduction in flux and output over increasing concentration compared to the direct contact variant [23]. The cost analysis section will thus evaluate costs only for AGMD and v-AGMD, which does not mean that DCMD modules can't be a viable option with an optimized membrane thickness. This research is, however, not a part of this work.

In Fig. 10 for DCMD at a channel length of $7 \mathrm{~m}$, approx. $8,6 \mathrm{~kg} / \mathrm{h}$ of distillate are produced at a GOR of $\sim 4$. Starting with the highest flux value of approx. $9,8 \mathrm{~kg} / \mathrm{m}^{2} \mathrm{~h}$ for the $0,7 \mathrm{~m}$ channel length, the DCMD variant breaks even with the v-AGMD channel setup at 1,4 $\mathrm{m}$ and with the AGMD channel setup at $3,5 \mathrm{~m}$ after which it remains constantly below the air gap variants flux wise due to the aforementioned higher sensitivity towards salinity for the same membrane type. At a channel length of $9,8 \mathrm{~m}$ the DCMD flux is $0,48 \mathrm{~kg} / \mathrm{m}^{2} \mathrm{~h}$, which is approx. half as much as the $0,91 \mathrm{~kg} / \mathrm{m}^{2} \mathrm{~h}$ for AGMD and $1,1 \mathrm{~kg} / \mathrm{m}^{2} \mathrm{~h}$ at the same channel length. Regarding the GOR values, the development increases with a slight change in inclination in the AGMD curve at $7 \mathrm{~m}$ channel length and a GOR of $\sim 3$. At the same channel length, v-AGMD presents a GOR value of 4,4 and is therefore the most efficient variant regarding thermal efficiency.

In the past, analysis for ZLD or hyper saline solutions with MD has frequently been performed assuming a DCMD experimental setup $[54,55]$ which does not always accurately depict the suitability and performance of MD for such applications. High driving forces of $35-55 \mathrm{~K}$ between the feed and permeate channel were applied using membranes with relatively thin active layers $(35-65 \mu \mathrm{m})$ [54]. As an example, with a driving force of $40 \mathrm{~K}\left(15^{\circ} \mathrm{C}\right.$ permeate and $55{ }^{\circ} \mathrm{C}$ feed $)$ and a concentration of $4 \mathrm{~mol} / \mathrm{L}$ a transmembrane flux of $\sim 18 \mathrm{~kg} / \mathrm{m}^{2} \mathrm{~h}$ was measured with a membrane that consisted of a $39 \mu \mathrm{m}$ active 
without a support structure [54]. However, the transfer of such results to a module level remains difficult as the driving force temperature difference must be expected to be much lower in an MD module design with internal heat recovery. Only one of the findings [24] used a driving force temperature difference as low as 10 Kelvin in the experimental set up. The result of these high applied driving forces is an overall high flux of up to $60 \mathrm{~kg} / \mathrm{h} \mathrm{m}^{2}$ and a reduced relative impact of the effect of salinity as often concluded. However, such results do not account for a viable method of internal heat recovery or realistic energy consumption in a full-scale MD module if interpreted without relevant context. Common driving force temperature differences as reported by institutes and industries manufacturing membrane distillation modules with a relevant sensible heat recovery (Aquastill bv., SolarSpring $\mathrm{GmbH}$ ) range within values of 2 [56] - approx. 10 Kelvin [20] and much lower flux values as a direct result. Studies with other types of MD modules operated at sub ambient pressure with different salinity level brines have been conducted and reported $[57,58]$ but follow a different method of heat recovery and require a vacuum pump.

To enable the selection of a suitable channel length for the batch process within a ZLD chain from 70.000-250.000 ppm, the same values at the final concentration are interpreted for $250.000 \mathrm{ppm}$. Differences in the progression of the values can be observed in both the upper and lower graph of Fig. 11. The largest impact of the higher salinity in the upper graph can be perceived in the DCMD values of both output, flux and GOR. After a channel length of $\sim 4,1 \mathrm{~m}$ the driving force is not high enough to overcome the effect of the increased salinity of the feed resulting in the cessation of the distillate output altogether due the absence of latent heat transfer. The air gap variants are not affected as strongly by the increased salinity. A slight decrease in output however is observed starting at a channel length of approx. $5,5 \mathrm{~m}$.

It is hereby noted that the following selection of a design channel length for the economic analysis is not the only possibility or the only concept. The decision on the selected length will be evaluated from a cost aspect and compared with the input decision made in Section 5.4 Affirmation of channel length selection. The following criteria lead to the choice of a $7 \mathrm{~m}$ channel length within the AGMD and v-AGMD channel configured modules:

- DCMD is excluded from the following economic study in Section 5 as the sensitivity towards salinity is too high in comparison to the air gap variants for the same membrane material. In depth analysis of heat recovery and parametric optimization strategies on DCMD is given in [59] and shows that for optimized membranes DCMD can very well be a viable option.

- At 70.000 ppm, the inclination of the output curves of AGMD and vAGMD flatten out. The increase in output is very minor after that point

- At $70.000 \mathrm{ppm}$, although the GOR still increases over a channel length of $7 \mathrm{~m}$, the flux becomes very low.

- At $240.000 \mathrm{ppm}$, the output begins to decrease after the $7 \mathrm{~m}$ channel mark and again flux becomes very low

- With regard to the discussion on pressure drop (Section 4.2), a $7 \mathrm{~m}$ channel length gives more freedom to operate also at higher feed flow rates without exceeding the boundary requirements for pressure drop in the MD module

\subsection{Output, specific energy consumption, GOR and flux for the batch process}

Fig. 12 shows the development of the performance values output, flux and GOR in AGMD and v-AGMD channel modules within the salinity range for the proposed batch process of ZLD. In the upper part of Fig. 12, values at $125.000 \mathrm{ppm}$ and $180.000 \mathrm{ppm}$ are added to the previously mentioned output and flux values (Figs. 8-11) for a $7 \mathrm{~m}$ channel length module at $70.000 \mathrm{ppm}$ and $240.000 \mathrm{ppm}$ feed inlet salinity to create a continuous curve. In the lower part of Fig. 12, GOR
Table 5

Mean values used for the economic analysis.

\begin{tabular}{lll}
\hline Value/type & Mean & Unit \\
\hline Output AGMD & 9,9 & {$[\mathrm{~kg} / \mathrm{h}]$} \\
Output v-AGMD & 12,2 & {$[\mathrm{~kg} / \mathrm{h}]$} \\
Flux AGMD & 1,0 & {$\left[\mathrm{~kg} / \mathrm{m}^{2} \mathrm{~h}\right]$} \\
Flux v-AGMD & 1,3 & {$\left[\mathrm{~kg} / \mathrm{m}^{2} \mathrm{~h}\right]$} \\
GOR AGMD & 2,5 & {$[-]$} \\
GOR v-AGMD & 3,7 & {$[-]$} \\
\hline
\end{tabular}

values are displayed for the same salinity region. Flux ranges from $1,2-0,8 \mathrm{~kg} / \mathrm{m}^{2} \mathrm{~h}$ for AGMD and $1,5-1 \mathrm{~kg} / \mathrm{m}^{2} \mathrm{~h}$ for v-AGMD between $70.000 \mathrm{ppm}$ and $240.000 \mathrm{ppm}$ inlet values. The highest GOR is 4,4 for v-AGMD at $70.000 \mathrm{ppm}$ and the lowest is 2,1 for AGMD at $240.000 \mathrm{ppm}$. The general trend observable in all curves of Fig. 12 towards lower values is assignable to the previously discussed impact of driving force loss due to the increasing salinity. All output values in the upper part of the figure are an expression of the corresponding flux values multiplied by the membrane area of $9,8 \mathrm{~m}^{2}$ for the $7 \mathrm{~m}$ channel length module channel. The higher thermodynamic efficiency of the VAGMD channel configuration clearly reflects in the significantly higher GOR values shown in the lower part of the graph.

Due to the nearly uniform inclination of these four curves, mean avg. values are derived as performance values for the batch and shown given in Table 5. These are used for the economic analysis in the next section.

\section{Cost analysis for membrane distillation systems}

\subsection{Capital expenditure (CAPEX) calculation for $M D$}

For the breakdown of MD capital costs, a division between module costs and rest of plant costs, subsequently named system costs is made. A further subdivision into currently possible costs for manufacturing of MD modules and prospective costs for the mid-term future ( $\sim 5$ years) was deemed necessary. It is based on the assumption that in the near future MD technology will possess more established and optimized procedures for the manufacturing of polymer components which form a module which will have resulted in a cost reduction of the production. Hence, a drop in the prices of MD modules should be taken into account to increase the validity of this analysis. For system costs no such prospective cost reduction scenario is necessary as the system components are all standard components.

A plate and frame type of MD module type has been considered in this cost analysis. The main components which form a plate and frame module are:

- Membrane
- Condenser polymer film
- Spacers
- Plates and frames
- Other components
- Labour (includes man hours for design and manufacturing)

A single plate and frame module has been defined as an entity with an effective membrane surface of $50 \mathrm{~m}^{2}$ for mass and heat transfer and with a countercurrent flow between the evaporator and condenser stream. Based on the required membrane surface to treat a specific feed flow, the number of modules can be calculated. Fig. 13 was developed based on vendor inputs and it depicts the specific capital costs $\left(€ / \mathrm{m}^{2}\right)$ required to manufacture AGMD and v-AGMD modules based on the required membrane surface to carry out the treatment process. Module costs are expected to undergo a cost reduction in the near future. Hence, the two curves plotted represent the current and the prospective module costs based on the membrane surface. 


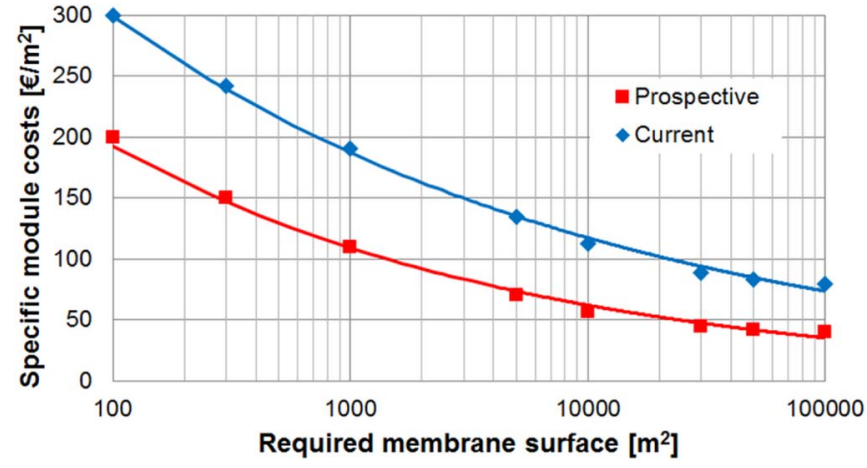

Fig. 13. Specific current and prospective capital costs for AGMD and v-AGMD modules membrane surface areas from 100 to $100.000 \mathrm{~m}^{2}$.

Table 6

Degression coefficients to estimate module CAPEX by capacity method for AGMD and vAGMD.

\begin{tabular}{llll}
\hline Type & $\begin{array}{l}\text { Reference membrane } \\
\text { surface }\left[\mathrm{m}^{2}\right]\end{array}$ & $\begin{array}{l}\text { Reference cost } \\
{[€]}\end{array}$ & $\begin{array}{l}\text { Degression } \\
\text { coefficient }\end{array}$ \\
\hline Current costs & 300 & 72.600 & 0,8 \\
Prospective costs & 300 & 45.000 & 0,74 \\
\hline
\end{tabular}

The general trend in Fig. 13 for both curves is due to the economy of scale. As the AGMD and the V-AGMD modules are similar in construction the costs represent both variants of MD. The degression coefficients have also been calculated in Table 6 for module costs with references and can be used in Eq. (8).

The fact that the CAPEX of a single AGMD and v-AGMD module is equal does not take into account the fact that the recovery rate for $\mathrm{v}$ AGMD is higher than that for AGMD. The impact being, that to treat a specific amount of feed water, you need a lower membrane surface for v-AGMD than for AGMD and thus lower costs for the former. Tables 8 and 9 show the membrane surface required for treatment of the 10, 100 and $1000 \mathrm{~m}^{3} / \mathrm{d}$ of wastewater together with the respective CAPEX and the number of modules required for treatment. The nomenclature used to is given in Table 7 .

From Tables 8 and 9, it can be observed that the v-AGMD variant is approximately $10-17 \%$ economically advantageous than its vacuumless variant regarding the investment costs for MD modules.

The CAPEX module costs are followed by costs for the rest of the plant or system costs i.e. costs of piping, other equipment including heat exchanger, pumps, tanks etc., installation costs, electrical and instrumentation costs etc. introduced in Section 2.1.1 and shown in Fig. 14.

Fig. 14 has been developed in order to estimate the specific system costs in relation to the number of modules in the system, as the system costs are rather a function of the number of modules than the surface. Costs such as piping, flow meters, temperature and pressure sensors and the controller costs that accompany these, depend on the number of modules and the interconnections between them. It is evident that the system costs for v-AGMD are higher than that for AGMD because of the vacuum pump and the additional piping for the same.

Costs for the hot side heat exchanger (Hex) are the only component costs, although incorporated in Fig. 13, are calculated from a reference capacity value $(\mathrm{kW} / \mathrm{K})$ and a degression coefficient of 0,8 [28].

Table 7

Symbols used for indicating capital cost for MD modules.

\begin{tabular}{lll}
\hline Type & Current & Prospective \\
\hline AGMD & C $_{\text {AGMD-C }}$ & C $_{\text {AGMD-P }}$ \\
v-AGMD & C $_{\text {VAGMD-C }}$ & C VAGMD-P \\
\hline
\end{tabular}

Titanium plates were chosen for resistance against corrosive salt water. An overall heat transfer coefficient value of $1,5 \mathrm{~kW} / \mathrm{m}^{2} \mathrm{k}$ for a steamwater plate heat exchanger was selected [60] and the logarithmic mean temperature difference for the heat exchanger was calculated for the highest feed salinity of $240.000 \mathrm{ppm}$ i.e. the highest delta $\mathrm{T}$ between condenser outlet and evaporator inlet. The cooling side heat exchanger is neglected. Table 10 presents the reference treatment capacity and calculated values for the AGMD case.

Having established all the components contributing to total CAPEX, a breakdown for AGMD and V-AGMD systems is presented in Figs. 15-17 based on the feed capacities.

To conclude the discussion on CAPEX, the v-AGMD system is more economic than the AGMD at current MD module manufacturing costs. In a prospective scenario, since additional vacuum equipment is assumed to remain at the same price as in the current state, the lower prospective module costs nearly amortize the advantage of the higher throughput per $\mathrm{m}^{2}$ of membrane surface in the vacuum system.

Table 11 summarizes the specific CAPEX costs per $\mathrm{m}^{3}$ of feed water treated in Euros for the current and prospective AGMD and v-AGMD systems.

\subsection{Operating expenditure (OPEX) for $M D$}

Operating costs are defined as the continuous costs required in day to day operation and have been categorised in the cost fundamentals Section 2.1.2. The thermal energy requirements in this work are assumed to be fulfilled by steam. Literature offers a range of values ranging from as low as $3 € /$ ton [30] to moderate values such as $10 € /$ ton [38] to higher values of $25 € /$ ton [61]. In the process industry, the true cost of steam depends on a variety of factors such as type of boiler, type of fuel, header pressure, pressure reduction mechanism used for steam etc. for which a whole steam circuit design with a huge number of assumptions would be required. The moderate value of $10 € /$ ton will be used for further analysis and comparison. Cost of electricity was based on consumption of the centrifugal feed pump and of the vacuum pump for v-AGMD. The efficiencies for the feed pump and vacuum pump were assumed to be $65 \%$ and $20 \%$ respectively and the unit price of electricity is defined as $0,1 € / \mathrm{kWh}[28]$.

Labour requirement for MD systems has been estimated for a $1000 \mathrm{~m}^{3} / \mathrm{d}$ (of permeate) desalination plant at two operators at a standard German salary of $40.000 € /$ annum each [28]. This value has been sized for the other two cases as per capacity.

Other components of OPEX such as service and maintenance, chemicals and insurance have been calculated as a percentage of the capital costs. Table 12 gives a summary the factors assumed.

One of the most crucial aspects of OPEX is the replacement costs for MD modules. The cost for the replacement of membranes $\left(C_{r e p}\right)$ is calculated for e.g. AGMD as:

$C_{\text {rep-AGMD }}=C_{A G M D-C / P^{*} f * Y_{F}}$

where $f$ is the percentage cost of the membranes with respect to the total module cost and $Y_{F}$ is the yearly replacement factor. The factor $f$ for MD modules is 0,1 with the present available unit price for membranes, when ordered on a large scale. As membrane life has been approximated at four years, the yearly replacement factor $\left(Y_{F}\right)$ becomes 0,25 .

A sample calculation for replacement costs for current AGMD modules for a treatment capacity of $1000 \mathrm{~m}^{3} / \mathrm{d}$ is shown below based on (Eq. (10)):

$$
\begin{aligned}
& C_{\text {rep-AGMD }}=C_{A G M D-C^{*} f^{*} Y_{F}} \\
& C_{\text {rep-AGMD }}=2.580 .840 * 0,1^{*} 0,25 \\
& C_{\text {rep-AGMD }}=64.521 \frac{€}{\text { year }}
\end{aligned}
$$

Figs. 18, 19 and 20 illustrate the calculated specific OPEX $\left(€ / \mathrm{m}^{3}\right)$ for 
Table 8

Estimated capital costs for current and prospective AGMD modules for three different treatment capacities; channel length $7 \mathrm{~m} ;$ feed flow rate $=250 \mathrm{~kg} / \mathrm{h}, \mathrm{T}_{\mathrm{ei}}=80{ }^{\circ} \mathrm{C}, \mathrm{T}_{\mathrm{ci}}=25{ }^{\circ} \mathrm{C}$.

\begin{tabular}{|c|c|c|c|c|c|c|}
\hline \multirow{3}{*}{$\begin{array}{l}\text { Capacity of treatment }\left[\mathrm{m}^{3} /\right. \\
\text { d] }\end{array}$} & \multirow{3}{*}{$\begin{array}{l}\text { Total required membrane surface } \\
{\left[\mathrm{m}^{2}\right]}\end{array}$} & \multirow{3}{*}{$\begin{array}{l}\text { No. of modules }\left[50 \mathrm{~m}^{2}\right. \\
\text { each }]\end{array}$} & \multicolumn{2}{|l|}{ Current } & \multicolumn{2}{|l|}{ Prospective } \\
\hline & & & Specific cost & $\begin{array}{l}\text { Total CAPEX for } \\
\text { modules }\end{array}$ & Specific cost & $\begin{array}{l}\text { Total CAPEX for } \\
\text { modules }\end{array}$ \\
\hline & & & {$\left[€ / \mathrm{m}^{2}\right]$} & {$\left[\mathrm{C}_{\mathrm{AGMD}-\mathrm{C}}\right][€]$} & {$\left[€ / \mathrm{m}^{2}\right]$} & {$\left[\mathrm{C}_{\mathrm{AGMD}-\mathrm{P}}\right][€]$} \\
\hline 10 & 294 & 6 & 242 & 71.148 & 150 & 44.100 \\
\hline 100 & 2.901 & 58 & 150 & 435.120 & 80 & 232.064 \\
\hline 1000 & 28.998 & 580 & 89 & 2.580 .840 & 45 & 1.304 .919 \\
\hline
\end{tabular}

the different feed capacities for the current and prospective AGMD and v-AGMD systems.

Comparing Figs. 18, 19 and 20, except for the lowest capacity vAGMD systems, the thermal energy costs dominate for all other systems ranging from $2,1-3,1 € / \mathrm{m}^{3}$. Thus if the total heating requirement is met by low grade waste heat, the specific OPEX has much scope for reduction. Labour costs for the lowest capacity at $2,6 € / \mathrm{m}^{3}$ are much higher compared to the other two cases. This is because the required working hours for labour on an MD plant cannot be scaled down in a linear fashion. The electrical energy costs for v-AGMD are higher than that for its AGMD counterpart on account of the energy required for the vacuum pump. But overall, the electrical energy costs (between $0,04-0,17 € / \mathrm{m}^{3}$ ) required to operate an MD plant are much lower in comparison to the required thermal energy costs. At the current and prospective unit price for membranes, the replacement costs account for $<0,5 € / \mathrm{m}^{3}$ at the highest.

Table 13 summarizes the specific OPEX costs per $\mathrm{m}^{3}$ of feed water processed in $€$ for AGMD and v-AGMD systems. In analogy to the specific CAPEX costs per $\mathrm{m}^{3}$ of feed water treated, the OPEX values show a similar succession regarding module types. At the highest capacity the values are lowest for all three module types in correspondence with the development of the costs for increasing membrane area (Fig. 13). The vAGMD system has economic advantages over the AGMD system on account of the lower thermal energy consumed by the former, in spite of consuming higher electrical energy due to the vacuum operation.

\subsection{Total specific costs for $M D$}

From the results of CAPEX and OPEX calculations for MD, total specific costs for wastewater are derived by adding the figures for specific CAPEX and specific OPEX and will be further used for comparison with MVC systems. Table 14 gives a comparison for specific costs for AGMD and v-AGMD systems for which the scale of economy can be observed. A lower capacity has a higher treatment cost and the cost reduces further as the capacity is increased.

Regarding the low impact of current or prospective module costs within the total costs, it should be pointed out that cost reductions assigned to optimized performance as well as improved materials has not been taken into account. Further cost reduction must be expected according to the potential developments to be expected in the near to mid term future.

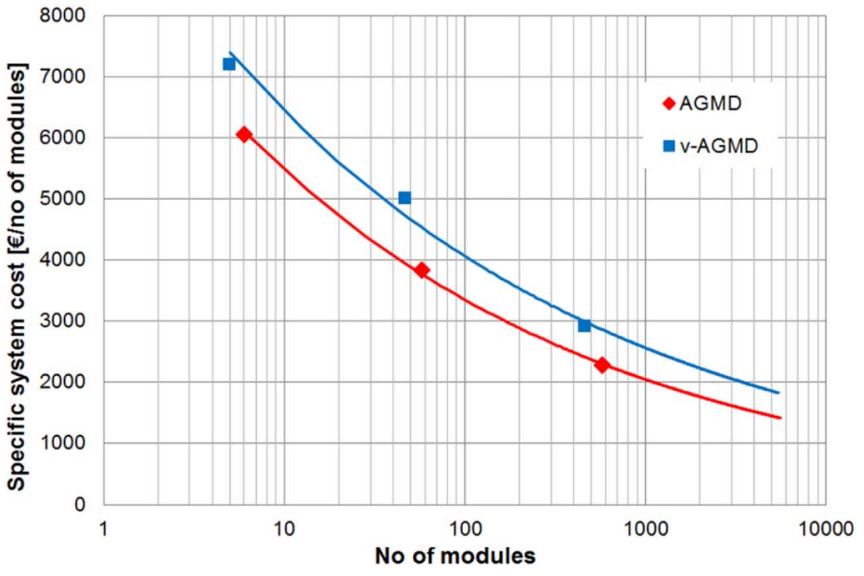

Fig. 14. Dependency of system costs on number of modules for AGMD and v-AGMD systems.

Table 10

Estimated costs of titanium plate heat exchanger for AGMD.

\begin{tabular}{llll}
\hline Treatment capacity $\left[\mathrm{m}^{3} / \mathrm{d}\right]$ & Capacity $[\mathrm{kW} / \mathrm{K}]$ & Cost $[€]$ & Degression \\
\hline Reference & 50 & 3.000 & 0,8 \\
10 & 7,4 & 650 & \\
100 & 72,8 & 4.050 & \\
1000 & 727,4 & 25.549 & \\
\hline
\end{tabular}

Membrane distillation technology has proven itself in the past to have an excellent utilization potential in combination with waste heat. As the optimal temperature required at the evaporator inlet is approx. $80{ }^{\circ} \mathrm{C}$, any form of waste heat above this temperature can be utilized in MD. In conclusion, an economic scenario has been added in Table 15 in which the cost of thermal energy is omitted for prospective MD systems. Costs for piping from waste heat source to MD heat exchanger have been neglected. The savings in total cost per $\mathrm{m}^{3}$ range from 27 to $60 \%$ for v-AGMD depending on the capacity and from 34 to $68 \%$ for AGMD for $10 \mathrm{~m}^{3} / \mathrm{d}-1000 \mathrm{~m}^{3} / \mathrm{d}$ respectively.

Table 9

Estimated capital costs for current and future v-AGMD modules for the different treatment capacities; channel length-7 m; feed flow: $250 \mathrm{~kg} / \mathrm{h}$, $\mathrm{T}_{\mathrm{ei}}=80{ }^{\circ} \mathrm{C}, \mathrm{T}_{\mathrm{ci}}=25^{\circ} \mathrm{C}$.

\begin{tabular}{|c|c|c|c|c|c|c|}
\hline \multirow{3}{*}{$\begin{array}{l}\text { Capacity of treatment }\left[\mathrm{m}^{3} /\right. \\
\text { d] }\end{array}$} & \multirow{3}{*}{$\begin{array}{l}\text { Total required membrane surface } \\
{\left[\mathrm{m}^{2}\right]}\end{array}$} & \multirow{3}{*}{$\begin{array}{l}\text { No. of modules }\left[50 \mathrm{~m}^{2}\right. \\
\text { each] }\end{array}$} & \multicolumn{2}{|l|}{ Current } & \multicolumn{2}{|l|}{ Prospective } \\
\hline & & & Specific cost & $\begin{array}{l}\text { Total CAPEX for } \\
\text { modules }\end{array}$ & Specific cost & $\begin{array}{l}\text { Total CAPEX for } \\
\text { modules }\end{array}$ \\
\hline & & & {$\left[€ / \mathrm{m}^{2}\right]$} & {$\left[\mathrm{C}_{\mathrm{AGMD}-\mathrm{C}}\right][€]$} & {$\left[€ / \mathrm{m}^{2}\right]$} & {$\left[\mathrm{C}_{\mathrm{vAGMD}-\mathrm{P}}\right][€]$} \\
\hline 10 & 235 & 5 & 250 & 58.800 & 155 & 36.456 \\
\hline 100 & 2.332 & 47 & 165 & 384.846 & 90 & 209.916 \\
\hline 1000 & 23.285 & 466 & 95 & 2.212 .056 & 50 & 1.164 .240 \\
\hline
\end{tabular}




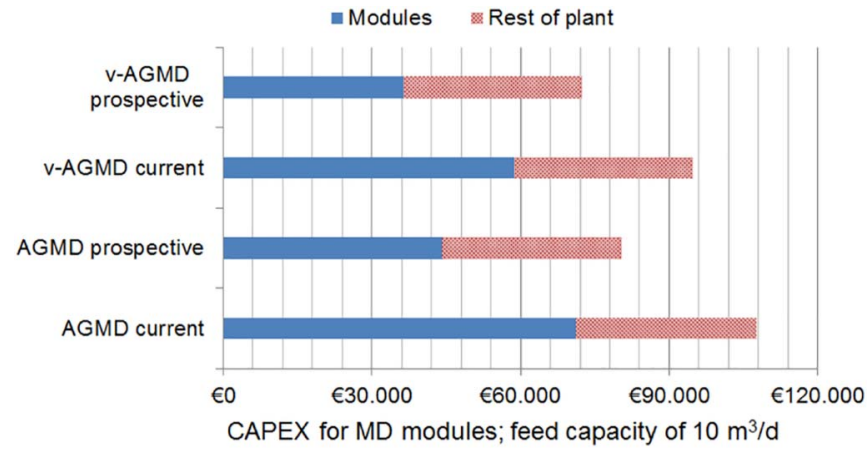

Fig. 15. Total capital costs for current and future AGMD and v-AGMD plants for a feed capacity of $10 \mathrm{~m}^{3} / \mathrm{d}$.

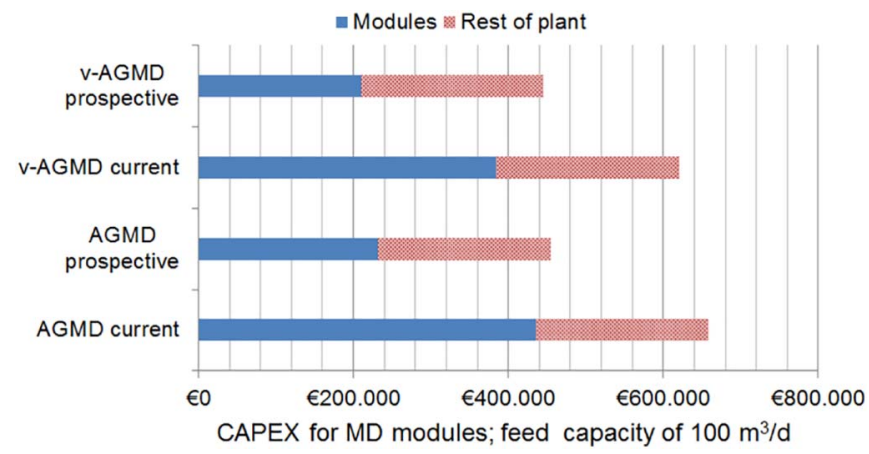

Fig. 16. Total capital costs for current and future AGMD and v-AGMD plants for a feed capacity of $100 \mathrm{~m}^{3} / \mathrm{d}$.

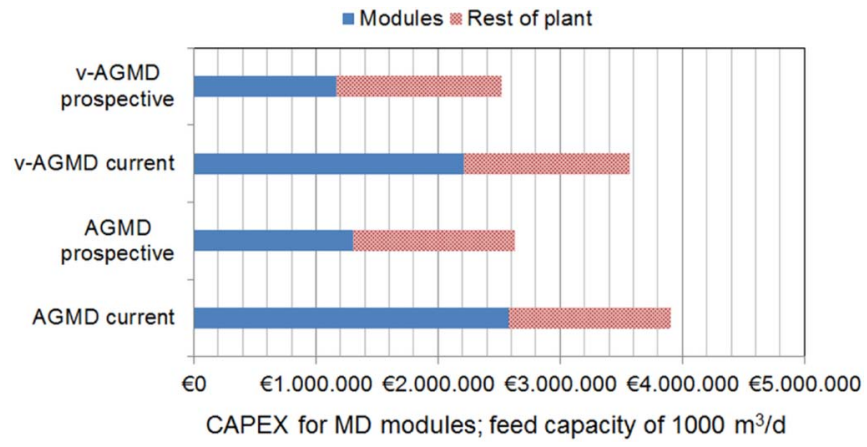

Fig. 17. Total capital costs for current and future AGMD and v-AGMD plants for a feed capacity of $1000 \mathrm{~m}^{3} / \mathrm{d}$.

\subsection{Affirmation of channel length selection}

In Section 4.4, factors affecting the selection of channel length were discussed and the conclusion was reached that a cost analysis should be used for the final validation of the selection. The lengths selected for this analysis are 4,9 m, 5,6 m, $7 \mathrm{~m}$ and 9,8 m. A channel length of $7 \mathrm{~m}$ was selected as nominal length. The costs incurred by the other length modules are compared to the costs incurred for the $7 \mathrm{~m}$ channel length module in Fig. 21. It depicts percentage values in comparison to a $7 \mathrm{~m}$
Table 12

Factors used for estimating other components that amount to total OPEX.

\begin{tabular}{llll}
\hline No & Type of cost & Factor & Reference \\
\hline 1 & Chemicals & $1 \%$ & {$[28]$} \\
2 & Service and maintenance & $2,5 \%$ & {$[28]$} \\
3 & Insurance & $0,5 \%$ & {$[28]$} \\
\hline
\end{tabular}

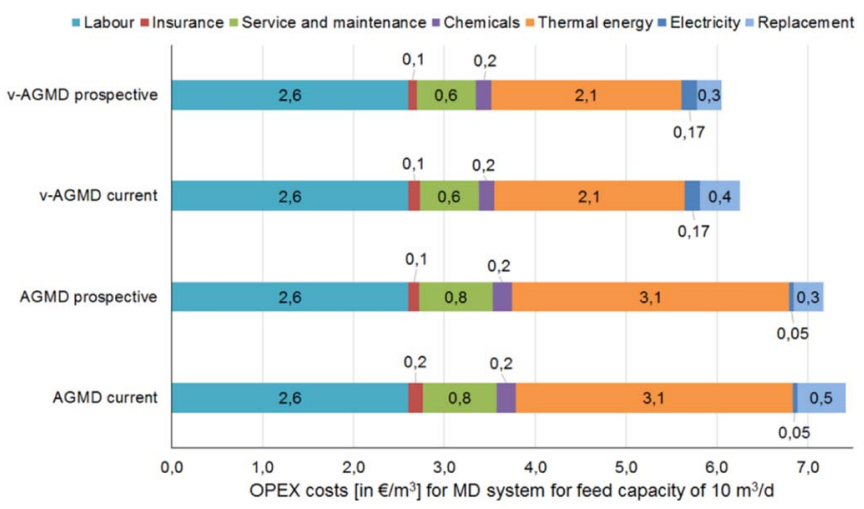

Fig. 18. The distribution of specific OPEX (in $€ / \mathrm{m}^{3}$ ) for current and prospective AGMD and v-AGMD systems for a treatment capacity of $10 \mathrm{~m}^{3} / \mathrm{d}$.

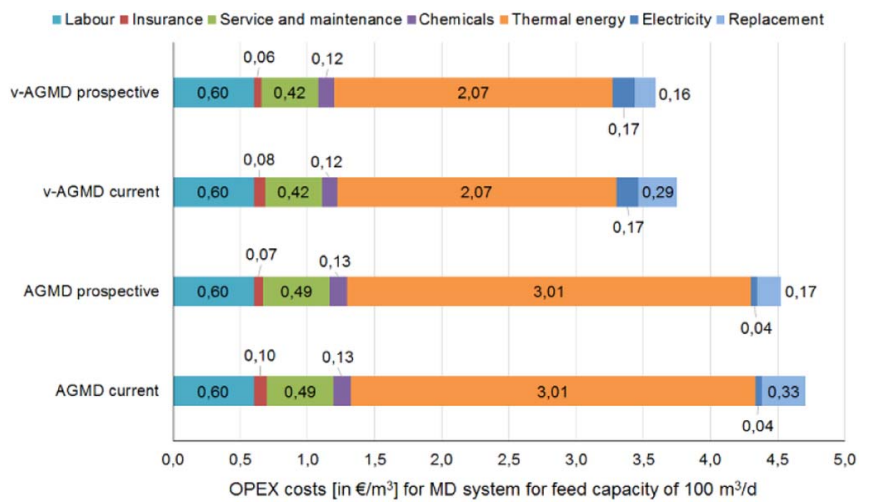

Fig. 19. The distribution of specific OPEX (in $€ / \mathrm{m}^{3}$ ) for current and prospective AGMD and v-AGMD systems for a treatment capacity of $100 \mathrm{~m}^{3} / \mathrm{d}$.

channel AGMD module at the operating conditions used throughout the economic analysis, namely a feed flow rate of $250 \mathrm{~kg} / \mathrm{h}$, an evaporator inlet temperature of $80^{\circ} \mathrm{C}$ and a condenser inlet temperature of $25^{\circ} \mathrm{C}$. A daily capacity of $1000 \mathrm{~m}^{3} / \mathrm{d}$ was assumed along with a batch operation from $70.000-250.000 \mathrm{ppm} \mathrm{NaCl}$ for a 20 year plant life. Comparing the $4,9 \mathrm{~m}$ length module to the $7 \mathrm{~m}$ module, it can be observed that the shorter channel results in 19\% less capital costs than the $7 \mathrm{~m}$ length module as it consists of less membrane, foil and spacer surface. Because of the shorter channel length, there is less heat recovery and hence the thermal energy cost is higher by $22 \%$. The net total costs per year are $14 \%$ higher compared to a $7 \mathrm{~m}$ channel module. Similar statistics can be observed for a $5,6 \mathrm{~m}$ length module at $-14 \%$ for CAPEX and $+14 \%$ of OPEX which are responsible for a total $9 \%$ cost disadvantage compared

Table 11

Summary of specific CAPEX in $€ / \mathrm{m}^{3}$ of feed water for MD.

\begin{tabular}{|c|c|c|c|c|c|c|}
\hline \multirow{2}{*}{$\begin{array}{l}\text { Capacity of treatment } \\
{\left[\mathrm{m}^{3} / \mathrm{d}\right]}\end{array}$} & \multicolumn{2}{|c|}{ AGMD $\left[€ / \mathrm{m}^{3}\right.$ of feed water] } & \multirow{2}{*}{$\begin{array}{l}\% \text { reduction in annual CAPEX for } \\
\text { prospective AGMD }\end{array}$} & \multicolumn{2}{|c|}{ v-AGMD $\left[€ / \mathrm{m}^{3}\right.$ of feed water $]$} & \multirow{2}{*}{$\begin{array}{l}\% \text { reduction in annual CAPEX for } \\
\text { prospective } v \text {-AGMD }\end{array}$} \\
\hline & Current & Prospective & & Current & Prospective & \\
\hline 10 & 2,4 & 1,8 & $25 \%$ & 2,1 & 1,6 & $24 \%$ \\
\hline 100 & 1,5 & 1,0 & $31 \%$ & 1,4 & 1,0 & $28 \%$ \\
\hline 1000 & 0,9 & 0,6 & $33 \%$ & 0,8 & 0,6 & $29 \%$ \\
\hline
\end{tabular}




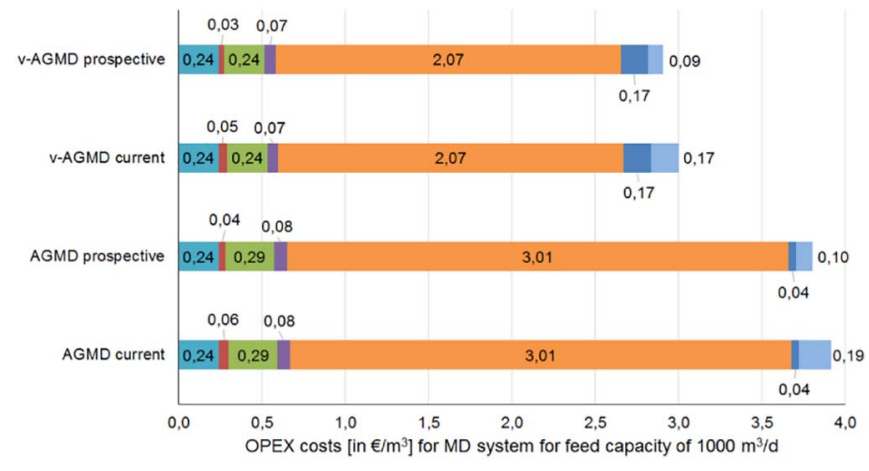

Fig. 20. The distribution of specific OPEX (in $€ / \mathrm{m}^{3}$ ) for current and prospective AGMD and v-AGMD systems for a treatment capacity of $1000 \mathrm{~m}^{3} / \mathrm{d}$.

with a $7 \mathrm{~m}$ length module. The $9,8 \mathrm{~m}$ length module is longer and more expensive than the $7 \mathrm{~m}$ length module in terms of CAPEX, resulting in a $41 \%$ excess in capital costs and the better internal heat recovery leads to a $4 \%$ advantage in the OPEX costs leading to a net $4 \%$ excess in the total costs per year for the $9,8 \mathrm{~m}$ channel length module. Thus, for the application of ZLD in this work the $7 \mathrm{~m}$ length module can be confirmed to be the most economic option.

\section{Cost analysis for MVC system}

In analogy to the analysis of the costs for MD, the CAPEX, OPEX and total amortized costs for state of the art brine concentrators are analyzed and summarized in the following sections.

\subsection{Capital expenditure (CAPEX) for MVC}

The cost of a MVC unit is considerably expensive because of the use of high grade metals to counter scaling and corrosion due to salts. Titanium and high grade stainless steel as a material of construction has been reported by [35]. The cost of the brine concentrator equipment in the whole ZLD scheme is one of the major contributors.

Four companies in the field of ZLD who supply brine concentrators were selected:

1. Veolia HPD

2. GE's water and process technologies

3. Vendor A

4. Vendor B

Some vendors were contacted in person in order to acquire preliminary cost values, some figures were extracted from company reports. Two vendor contacts are anonymized. Fig. 22 has been plotted based on the CAPEX costs collected from reports $[25,35]$ or provided by vendors (anonymized) and contain MVC equipment plus installation costs for different capacities. It must be noted that cost values from Veolia, GE water and vendor A has been converted from USD to Euros (1 USD = 0,9 Eur; 07/2017).

Information in Table 16 represents the capital costs calculated for the assumed treatment capacities based on Fig. 22 and the reference capacity method with a degression coefficient of 0,66 [35]. Also data for Veolia and GE water extracted from [25,35] was obtained during the year 2006 and hence has been converted with the use of the chemical engineering plant cost index (CEPCI) (Eq. (8)). Due to nonavailability of the latest CEPCI, the nearest available cost index value for 2014 was used for calculation. The CEPCI values for the year 2006 and 2014 are 499,6 and 576,1 respectively.

For the lowest capacity of $10 \mathrm{~m}^{3} / \mathrm{d}$, a high variance of 2,8 -fold can be observed between Vendor B and Vendor A (Table 16). For a system capacity of $1000 \mathrm{~m}^{3} / \mathrm{d}$ Vendor A is still $1,95 \times$ more costly than Vendor B. Thus, a cost mean value of the different inputs for the different reference capacities was calculated and is used subsequently.

Table 17 gives the mean CAPEX for all three reference capacities along with its amortized value per year and specific CAPEX per $\mathrm{m}^{3}$ of feed water. All values for specific CAPEX decreases as the capacity is increased which indicates a scale of economy. For example the specific CAPEX per $\mathrm{m}^{3}$ of feed water to be treated is approximately less than half at $1,7 € / \mathrm{m}^{3}$ at a reference capacity of $1000 \mathrm{~m}^{3} / \mathrm{d}$ compared to $3,7 € / \mathrm{m}^{3}$ for a reference capacity of $100 \mathrm{~m}^{3} / \mathrm{d}$.

\subsection{Operating expenditure (OPEX) for $M V C$}

The operating costs that occur during MVC operation can be listed as:

\author{
1. Electrical energy \\ 2. Labour \\ 3. Service and maintenance \\ 4. Chemicals \\ 5. Insurance
}

The electric energy consumption can be mainly assigned to the power required by the compressor. The value of electric energy consumption for the desalination of seawater varies between 20 and $30 \mathrm{kWh} / \mathrm{m}^{3}$ of distilled fresh water and is sometimes given as high as $55,4 \mathrm{kWh} / \mathrm{m}^{3}$ (Vendor B). Other literature also suggests similar values 26,84 to $52,8 \mathrm{kWh} / \mathrm{m}^{3}$ of distilled fresh water [35]. Since the electric consumption varies by a big margin, in this work the average value provided by [62], viz. $39,8 \mathrm{kWh} / \mathrm{m}^{3}(0,1 \mathrm{kWh} / \mathrm{gal})$ will be used for cost calculation. The costs per year for the $1000 \mathrm{~m}^{3} / \mathrm{d}$ treatment capacity unit are shown below:

$$
\begin{aligned}
C_{\text {electrical }} & =\dot{q}_{\text {permeate }}{ }^{*} \text { unit price of electricity*specific energy consumption } \\
C_{\text {electrical }} & =235.085 \frac{\mathrm{m}^{3}}{\mathrm{year}} * 1 \frac{€}{\mathrm{kWh}}^{*} 39,8 \frac{\mathrm{kWh}}{\mathrm{m}^{3}} \\
C_{\text {electrical }} & =935.637 \frac{€}{\text { year. }}
\end{aligned}
$$

The permeate per year for a capacity of $1000 \mathrm{~m}^{3} / \mathrm{d}$ of feed water is calculated from the concentration of the MVC unit from $70.000 \mathrm{ppm}$ to $250.000 \mathrm{ppm}$, an overall recovery rate of $72 \%$ is achieved, for $8000 \mathrm{~h}$ per year.

The labour requirements are provided in [25] and have been estimated and formulated into a table below based on an average German salary for a skilled technician:

The service and maintenance, chemical and insurance costs have

\begin{tabular}{|c|c|c|c|c|c|c|}
\hline \multirow{2}{*}{$\begin{array}{l}\text { Capacity of treatment } \\
{\left[\mathrm{m}^{3} / \mathrm{d}\right]}\end{array}$} & \multicolumn{2}{|c|}{ AGMD $\left[€ / \mathrm{m}^{3}\right.$ of feed water $]$} & \multirow{2}{*}{$\begin{array}{l}\% \text { reduction in annual OPEX for } \\
\text { prospective AGMD }\end{array}$} & \multicolumn{2}{|c|}{ v-AGMD $\left[€ / \mathrm{m}^{3}\right.$ of feed water $]$} & \multirow{2}{*}{$\begin{array}{l}\% \text { reduction in annual OPEX for } \\
\text { prospective } \mathrm{v} \text {-AGMD }\end{array}$} \\
\hline & Current & Prospective & & Current & Prospective & \\
\hline 10 & 7,4 & 7,2 & $3 \%$ & 6,3 & 6,1 & $3 \%$ \\
\hline 100 & 4,7 & 4,5 & $4 \%$ & 3,8 & 3,6 & $5 \%$ \\
\hline 1000 & 3,9 & 3,8 & $2,5 \%$ & 3,0 & 2,9 & $3 \%$ \\
\hline
\end{tabular}

Table 13

Summary of the specific OPEX values for MD. 
Table 14

Specific total costs for current and future MD systems according to treatment capacity.

\begin{tabular}{|c|c|c|c|c|c|c|}
\hline \multirow{2}{*}{$\begin{array}{l}\text { Capacity of treatment } \\
{\left[\mathrm{m}^{3} / \mathrm{d}\right]}\end{array}$} & \multicolumn{2}{|c|}{ AGMD $\left[€ / \mathrm{m}^{3}\right.$ of feed water $]$} & \multirow{2}{*}{$\begin{array}{l}\% \text { reduction in total annual costs for } \\
\text { prospective AGMD }\end{array}$} & \multicolumn{2}{|c|}{ v-AGMD $\left[€ / \mathrm{m}^{3}\right.$ of feed water] } & \multirow{2}{*}{$\begin{array}{l}\% \text { reduction in total annual costs for } \\
\text { prospective v-AGMD }\end{array}$} \\
\hline & Current & Prospective & & Current & Prospective & \\
\hline 10 & 9,8 & 9,0 & $8 \%$ & 8,3 & 7,7 & $7 \%$ \\
\hline 100 & 6,2 & 5,5 & $11 \%$ & 5,1 & 4,6 & $9 \%$ \\
\hline 1000 & 4,8 & 4,4 & $8 \%$ & 3,8 & 3,5 & $7 \%$ \\
\hline
\end{tabular}

Table 15

Specific costs in $€ / \mathrm{m}^{3}$ with and without free waste heat for prospective AGMD and vAGMD systems (W/O - without).

\begin{tabular}{|c|c|c|c|c|c|c|}
\hline \multirow{2}{*}{$\begin{array}{l}\text { Capacity of } \\
\text { treatment } \\
{\left[\mathrm{m}^{3} / \mathrm{d}\right]}\end{array}$} & \multicolumn{2}{|c|}{$\begin{array}{l}\text { AGMD }\left[€ / \mathrm{m}^{3} \text { of }\right. \\
\text { feed water }]\end{array}$} & \multirow{2}{*}{$\begin{array}{l}\% \text { reduction } \\
\text { in total } \\
\text { annual costs } \\
\text { for waste } \\
\text { heat case } \\
\text { (AGMD) }\end{array}$} & \multicolumn{2}{|c|}{$\begin{array}{l}\mathrm{v}-\mathrm{AGMD}\left[€ / \mathrm{m}^{3}\right. \\
\text { of feed water] }\end{array}$} & \multirow{2}{*}{$\begin{array}{l}\% \text { reduction } \\
\text { in total } \\
\text { annual costs } \\
\text { for waste } \\
\text { heat case ( } \mathrm{v} \text { - } \\
\text { AGMD) }\end{array}$} \\
\hline & $\begin{array}{l}\text { W/O } \\
\text { waste } \\
\text { heat }\end{array}$ & $\begin{array}{l}\text { with } \\
\text { waste } \\
\text { heat }\end{array}$ & & $\begin{array}{l}\text { W/O } \\
\text { waste } \\
\text { heat }\end{array}$ & $\begin{array}{l}\text { with } \\
\text { waste } \\
\text { heat }\end{array}$ & \\
\hline 10 & 9,0 & 5,9 & $34 \%$ & 7,7 & 5,6 & $27 \%$ \\
\hline 100 & 5,5 & 2,5 & $54 \%$ & 4,6 & 2,5 & $45 \%$ \\
\hline 1000 & 4,4 & 1,4 & $69 \%$ & 3,5 & 1,4 & $60 \%$ \\
\hline
\end{tabular}

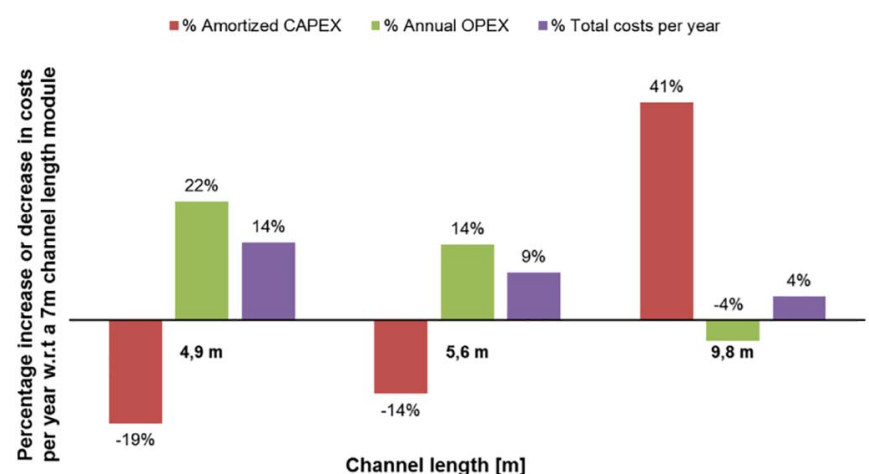

Fig. 21. Percentage of amortized capital costs, operating costs and total costs for various channel length modules with a module of length $7 \mathrm{~m}$ for 20 years plant life time.

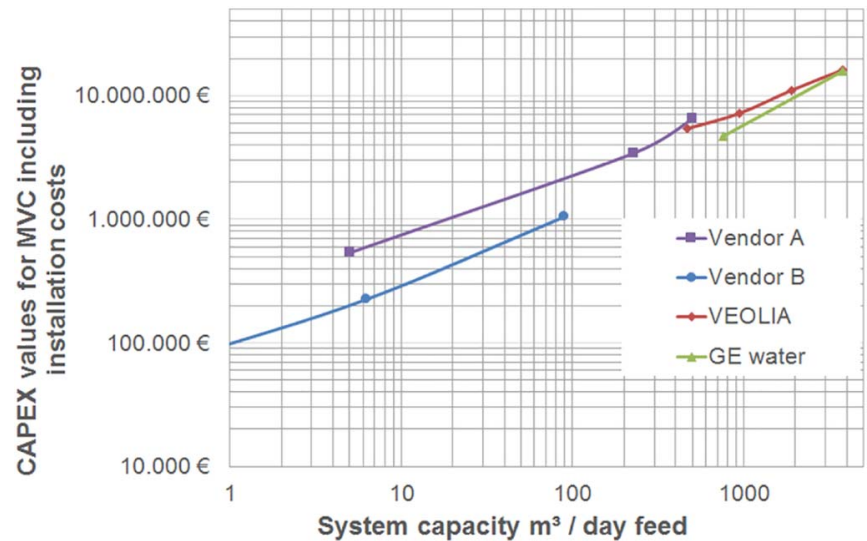

Fig. 22. The operating cost distribution for a brine concentrator (for a treatment capacity of $\left.1000 \mathrm{~m}^{3} / \mathrm{d}\right)$.

been assumed to be a percentage of the CAPEX of the MVC. Table 19 displays the respective percentages:

Fig. 23 depicts the distribution of specific OPEX in $€ / \mathrm{m}^{3}$ for an MVC plant which was estimated for the different feed capacities. The OPEX breakdown is similar to the MD breakdown as the energy consumption holds a major share in the diagram. Specific costs for labour also follow a similar trend as they are higher than the energy consumption for the lowest capacity but decrease considerably with an increase in capacity.
Table 16

Final CAPEX values for brine concentrators for different capacities with mean CAPEX.

\begin{tabular}{lllll}
\hline \multirow{2}{*}{ No } & Source & \multicolumn{3}{l}{ Estimated CAPEX for treatment capacity $\left[\mathrm{m}^{3} / \mathrm{d}\right]$ in $[€]$} \\
\cline { 3 - 5 } & & 10 & 100 & 1000 \\
\hline 1 & Veolia HPD - & 490.697 & 2.242 .919 & 8.574 .618 \\
& 2014 & & & \\
2 & GE Water - 2014 & 314.391 & 1.437 .045 & 6.565 .444 \\
3 & Vendor A - 2016 & 839.106 & 1.969 .376 & 10.069 .267 \\
4 & Vendor B - 2016 & 302.033 & 1.124 .457 & 5.139 .761 \\
5 & Mean & 486.557 & 1.693 .449 & 7.587 .273 \\
\hline
\end{tabular}

Table 17

CAPEX breakdown for MVC systems for different daily capacities.

\begin{tabular}{|c|c|c|c|}
\hline \multirow[t]{2}{*}{ CAPEX breakdown } & \multicolumn{3}{|c|}{$\begin{array}{l}\text { CAPEX for brine concentrators for different capacities } \\
{\left[\mathrm{m}^{3} / \mathrm{d}\right] \text { in }[€]}\end{array}$} \\
\hline & 10 & 100 & 1000 \\
\hline $\begin{array}{l}\text { MVC unit (incl. } \\
\text { installation) }\end{array}$ & 486.557 & 1.693 .449 & 7.587 .273 \\
\hline $\begin{array}{l}\text { Amortized CAPEX per } \\
\text { year }\end{array}$ & 35.802 & 124.607 & 558.285 \\
\hline $\begin{array}{l}\text { Specific CAPEX }\left[€ / \mathrm{m}^{3} \text { of }\right. \\
\text { feed water }]\end{array}$ & 10,8 & 3,7 & 1,7 \\
\hline
\end{tabular}

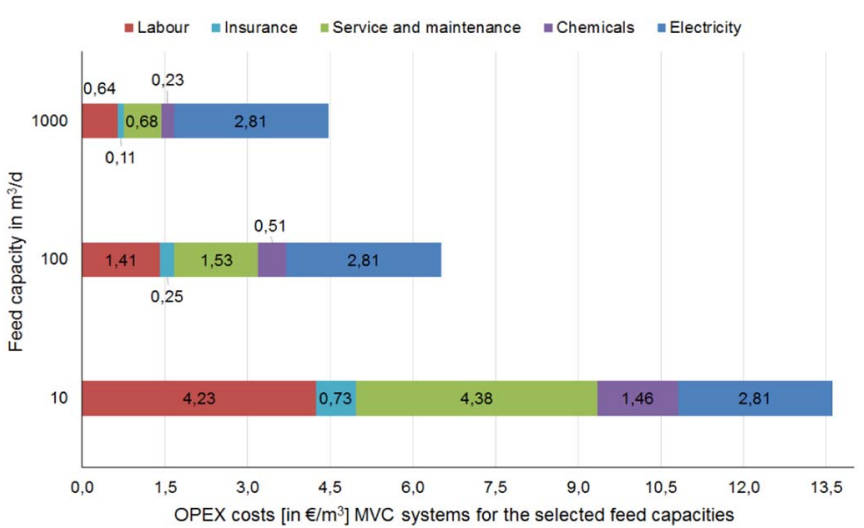

Fig. 23. Distribution of specific OPEX (in $€ / \mathrm{m}^{3}$ ) for the selected capacities for MVC systems.

Table 18

Estimation for labour costs for brine concentrators estimated from [25]. [Calculated for an hourly salary of 23,5 € for a technician (E8, Stufe 6)].

\begin{tabular}{llll}
\hline No & Treatment capacity $\left[\mathrm{m}^{3} / \mathrm{d}\right]$ & Man hour load per year & Costs per year $[€]$ \\
\hline 1 & 10 & 600 & 14.100 \\
2 & 100 & 2000 & 47.000 \\
3 & 1000 & 9000 & 211.500 \\
\hline
\end{tabular}

The non-linearity of man hours required as per capacity is evident from Table 18.

Fig. 24 depicts the real cost figures for the operating costs for the 
Table 19

Factors used for estimating other components that contribute to total OPEX for a brine concentrator.

\begin{tabular}{llll}
\hline No & Type of cost & Factor & Reference \\
\hline 1 & Service and maintenance & $3 \%$ & {$[63,25]$} \\
2 & Chemicals & $1 \%$ & {$[63,25]$} \\
3 & Insurance & $0,5 \%$ & - \\
\hline
\end{tabular}

Table 20

Specific total costs for brine concentrators.

\begin{tabular}{ll}
\hline Brine concentrator & \\
\hline Capacity of treatment $\left[\mathrm{m}^{3} / \mathrm{d}\right]$ & Specific total costs $\left[€ / \mathrm{m}^{3}\right.$ of feed water $]$ \\
\hline 10 & 24,4 \\
100 & 10,3 \\
1000 & 6,1 \\
\hline
\end{tabular}

Table 21

ROI values for different payback periods with or without an available waste heat source.

\begin{tabular}{llll}
\hline $\begin{array}{l}\text { Treatment } \\
\text { capacity }\left[\mathrm{m}^{3} / \mathrm{d}\right]\end{array}$ & $\begin{array}{l}\text { Payback period } \\
\text { for CAPEX } \\
\text { [years] }\end{array}$ & $\begin{array}{l}\text { ROI for future AGMD } \\
\text { over MVC without } \\
\text { waste heat [years] }\end{array}$ & $\begin{array}{l}\text { ROI for future } \\
\text { AGMD over MVC } \\
\text { with waste heat } \\
\text { [years] }\end{array}$ \\
\hline \multirow{2}{*}{10} & 2 & 0,34 & 0,33 \\
& 4 & 0,60 & 0,56 \\
100 & 7 & 0,90 & 0,81 \\
& 2 & 0,63 & 0,55 \\
1000 & 4 & 1,12 & 0,90 \\
& 7 & 1,67 & 1,22 \\
& 2 & 0,92 & 0,68 \\
& 4 & 1,65 & 1,01 \\
\hline
\end{tabular}

assumed capacities. Similar to Table 17 , the specific costs are at maximum for a lower capacity of $10 \mathrm{~m}^{3} / \mathrm{d}$ with specific OPEX at $13,6 € / \mathrm{m}^{3}$ and decrease as the capacity increases. For a treatment capacity of $1000 \mathrm{~m}^{3} / \mathrm{d}$, specific OPEX is $4,5 € / \mathrm{m}^{3}$.

\subsection{Total specific costs for MVC}

Table 20 displays the total specific costs for MVC systems with respect to treatment capacity. As for MD, these values are calculated by adding the specific costs for CAPEX and OPEX.

\section{Cost comparison between MD and MVC}

The costs calculated with the elaborated MD system design for a

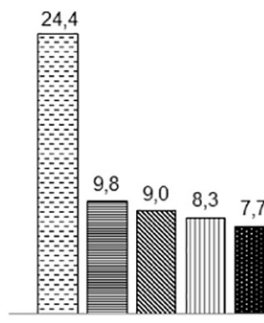

10
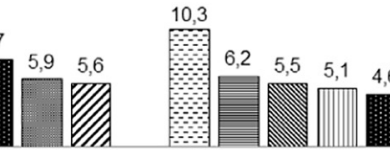

100

Treatment capacity $\left[\mathrm{m}^{3} / \mathrm{d}\right]$

EMVC

曰AGMD current

巴v-AGMD current

V-AGMD prospective

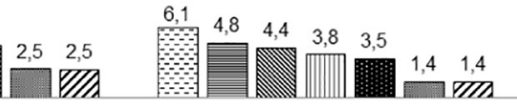

1000

\section{Return on investment (ROI)}

As a simple performance measure to indicate the efficiency of the investment, a comparative return on investment (ROI) was calculated. The potential ROI can serve as motivation to further develop a new technology such as MD. In order to compare MD to MVC as the state of the art technology, the return on investment is calculated as:
Fig. 24. Comparison of specific costs for treating wastewater at different capacities. Summary of the cost figures obtained in this research compares MVC systems to current, prospective and waste heat operated AGMD and v-AGMD systems.

V V-AGMD waste heat (prospective) 


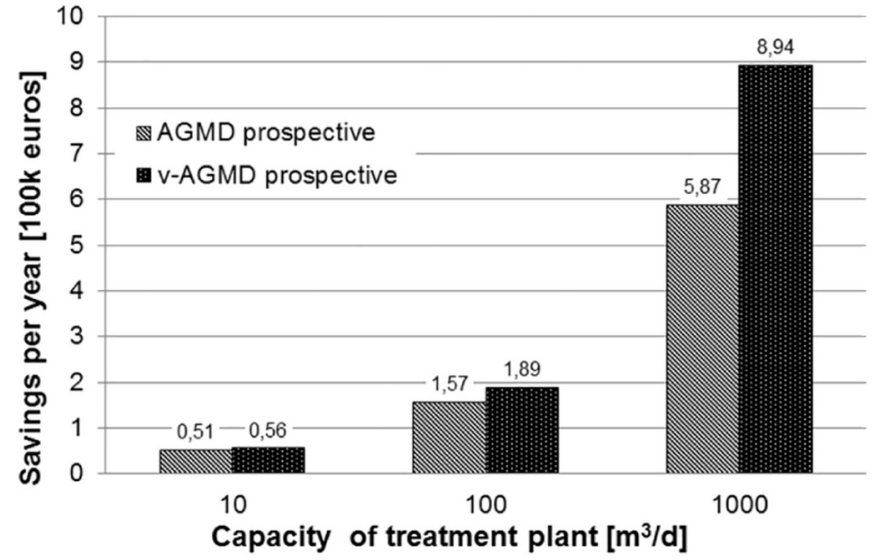

Fig. 25. Monetary savings per year for prospective MD over MVC.

$$
\mathrm{ROI}(\text { years })=\frac{\text { CAPEX for } M D \text { (euros) }}{\text { Annual savings for } M D \text { over MVC }\left(\frac{\text { euros }}{\text { year }}\right)}
$$

The annual savings are based on an amortized annual CAPEX-value which is dependent on the assumed payback period for the investment. By varying this payback period it is possible to assess the economic superiority of one technology over the other by using the return on investment as a base. A shorter ROI is preferred. In this work, the payback period for the CAPEX has been varied between 2, 4 and 7 and its corresponding ROI have been calculated. In Table 21 the ROI's for the cases of a steam supplied MD system and a waste heat supplied MD system for the various treatment capacities are given.

If the MD system is supplied via steam, higher treatment capacities $\left(1000 \mathrm{~m}^{3} / \mathrm{d}\right)$ lead to an ROI of over 3 years. For lower capacities of $100 \mathrm{~m}^{3} / \mathrm{d}$ and below are well below 2 . These values correspond with the lower savings for MD over MVC at higher capacities as shown in Fig. 24. For a 2-7 year payback period ROI is under 3 years in all cases.

\section{Conclusion}

A membrane distillation system was compared to a mechanical vapour compression system as an alternative step in the zero liquid discharge scheme of processing for highly saline wastewaters. Firstly, a MD module design for a batch process within a concentration range between 70.000 and $250.000 \mathrm{ppm}$ of $\mathrm{NaCl}$ was carried out. The flow rate was selected at $250 \mathrm{~kg} / \mathrm{h}$ per module, based on a pressure drop, output and GOR analysis for the range of concentration. In this work, a $7 \mathrm{~m}$ channel length per module was selected for the application based on a trade-off between output and specific energy consumption which was confirmed to be the most economical of the given possibilities by the cost analysis. DCMD is discussed as a possible channel variant, but not used in the cost analysis due to the lack of currently available suitable membrane material (thicker membranes) to make the variant thermodynamically meaningful for the high salt concentrations in the feed.

A detailed costs analysis for MD under current production circumstances revealed that both AGMD and v-AGMD are more economical than the MVC as a ZLD step throughout the capacity range selected. For the selected feed capacity of $10 \mathrm{~m}^{3} / \mathrm{d}$, the range of specific costs for current and prospective MD fall between 9 and $9,8 € / \mathrm{m}^{3}$ in comparison to $24,4 € / \mathrm{m}^{3}$ for MVC; Similarly for $1000 \mathrm{~m}^{3} / \mathrm{d}$, treatment costs for current and prospective MD lie between $4,4-4,8 € / \mathrm{m}^{3}$ compared to $6,1 € / \mathrm{m}^{3}$ for an MVC system. Higher gains are expected in the future when MD manufacturers have optimized production technologies with savings from $€ 580.000$ to $€ 890.000$ per year compared to MVC for the largest capacity selected.

Within the MD variants, the v-AGMD has lower costs than the
AGMD variant on both current and prospective accounts, provided if heat energy is not free of cost. In the case of available waste heat however, the specific treatment costs for prospective AGMD and vAGMD variants for capacities 100 and $1000 \mathrm{~m}^{3} / \mathrm{d}$ differ by $0,02 € / \mathrm{m}^{3}$ only with the former being more economical. In comparison with MVC with waste heat available MD can potentially be $\sim 75 \%$ cheaper.

The costs analysis shows that MD technology is a technically viable and cost effective solution for use in a ZLD system. It fills the gap between the output RO concentration $\sim 70.000 \mathrm{ppm}$ and the brine crystallizer steps. A return on investment analysis also shows that for payback periods of capital between 2 and 7 years, steam powered MD has an ROI of 2,5 years at maximum compared to MVC. This scenario is better for MD when waste heat is available as then the maximum ROI is 1,3 year for a capacity of $1000 \mathrm{~m}^{3} / \mathrm{d}$, which shows MD can be a potential substitute to MVC in the future.

Regarding an outlook towards further work to be conducted, the assumptions made must be validated in practice. Actual membrane and module lifetime should be investigated at least on a pilot scale in long term testing. Also, experience on the necessary pre-treatment must be gained in order to know if the extent of mineral removal before the RO stage is sufficient enough to cover the requirements for the MD stage. Ultimately, detailed engineering of a MD system as described in this work is needed to validate all assumptions made.

\section{Nomenclature}

A membrane area $\left[\mathrm{m}^{2}\right]$

AGMD air gap membrane distillation

C Costs [€]

CAPEX capital costs

$c_{p} \quad$ specific heat capacity $[\mathrm{kJ} / \mathrm{kg} \mathrm{K}]$

$\mathrm{d} \quad$ pore diameter $[\mu \mathrm{m}]$

DCMD direct contact membrane distillation

$f \quad$ percentage cost of membrane factor [-]

GOR gained output ratio [-]

h height $[\mathrm{m}]$

$K \quad$ plant capacity $\left[\mathrm{m}^{3} /\right.$ day $]$

$m \quad$ degression coefficient

$\dot{m} \quad$ mass flow $[\mathrm{kg} / \mathrm{h}]$

MD membrane distillation

MVC mechanical vapour compression

$j \quad$ transmembrane flux $\left[\mathrm{kg} / \mathrm{m}^{2} \mathrm{~h}\right]$

L channel length [m]

$P \quad$ power [W]

Pvp pressure vacuum pump [bar (a)]

$\dot{q} \quad$ fresh water produced in one year $\left[\mathrm{m}^{3} /\right.$ year]

RO reverse osmosis

ROI return on investment [years]

S salinity [ppm]

SEC specific energy consumption $\left[\mathrm{kWh} / \mathrm{m}^{3}\right]$

$\mathrm{T} \quad$ temperature $\left[{ }^{\circ} \mathrm{C}\right]$

TDS total dissolved solids [ppm]

$\varepsilon \quad$ porosity [-]

$\delta \quad$ thickness [m]

$\rho \quad$ density $\left[\mathrm{kg} / \mathrm{m}^{3}\right]$

v-AGMD vacuum air gap membrane distillation

VMD vacuum membrane distillation

$Y_{F} \quad$ yearly replacement factor [-]

ZLD zero liquid discharge

Indices

AG air gap

B backing

C condenser

$\mathrm{C} / \mathrm{P} \quad$ current/prospective 


$\begin{array}{ll}\text { CAP } & \text { capital } \\ \text { ci } & \text { condenser inlet } \\ d & \text { distillate } \\ \mathrm{E} & \text { evaporator } \\ e i & \text { evaporator inlet } \\ e l & \text { electrical } \\ f & \text { feed } \\ i & \text { interest rate } \\ \mathrm{M} & \text { membrane } \\ n & \text { expected plant life } \\ \text { OPEX } & \text { operating costs } \\ \text { perm } & \text { permeate } \\ \text { ref } & \text { reference } \\ r e p & \text { replacement } \\ \mathrm{S} & \text { spacer } \\ \text { th } & \text { thermal } \\ \mathrm{VP} & \text { vacuum pump }\end{array}$

\section{Acknowledgements}

This work was funded by the BMBF project ReSoWas (03FH009PX4) and is dedicated to the late Marcel Wieghaus for his vision on membrane distillation.

\section{References}

[1] A. Alkhudhiri, Membrane distillation: a comprehensive review, Desalination 287 (1-7) (2012).

[2] A. Alklaibi, N. Lior, Transport analysis of air-gap membrane distillation, J. Membr. Sci. 255 (1-2) (2005) 239-253.

[3] G. Liu, Theoretical and experimental studies on air gap membrane distillation, Heat Mass Transf. 34 (4) (1998) 329-335.

[4] N. Dow, Pilot trial of membrane distillation driven by low grade waste heat: membrane fouling and energy assessment, Desalination 391 (August 2016) 30-42.

[5] Bodell, "Silicone rubber vapour diffusion in saline water distillation". USA Patent 285,032, 1963.

[6] Bandini, Sarti, Concentration of must through vacuum membrane distillation, Desalination 149 (2002) 253-259.

[7] N. Hilal, S. Gunko, S. Verbych, M. Bryk, Concentration of apple juice using direct contact membrane distillation, Desalination 190 (2006) 117-124.

[8] F. Macedonio, C. Quist-Jensen, C. Coindi, A. Cassano, S. Aljlil, O. Alharbi, E. Drioli, Direct contact membrane distillation for the concentration of clarified orange juice, J. Food Eng. 187 (2016) 37-43.

[9] A. Hausmann, P. Sanciolo, T. Vasiljevic, M. Weeks, K. Schroen, S. Grey, M. Duke, Fouling of dairy components on hydrophobic polytetrafluoroethylene (PTFE) membranes for membrane distillation, J. Membr. Sci. 442 (2013) 149-159.

[10] S. Al-Asheh, F. Banat, M. Qtaishat, M. Al-Khateeb, Concentration of sucrose solutions via vacuum membrane distillation, Desalination (2006) 60-68.

[11] J. Grzechulska-Damszel, M. Tomaszewska, A. Morawski, Integration of photocatalysis with membrane processes for purification of water contaminated with organic dyes, Desalination 241 (2009) 118-126.

[12] H. Li, Y. Huo, Z. Xie, M. Hoang, R. Caruso, X. Wang, Methyl orange removal by combined visible-light photocatalysis and membrane distillation, Dyes Pigments 98 (2013) 106-112.

[13] Z. Ding, L. Liu, Z. Li, R. Ma, Z. Yang, Experimental study of ammonia removal from water by membrane distillation (MD): the comparison of three configurations, J. Membr. Sci. 286 (2006) 93-103.

[14] R. Ma, M. El-Bourawi, M. Khayet, Z. Ding, Z. Li, X. Zhang, Application of vacuum membrane distillation for ammonia removal, J. Membr. Sci. 301 (2007) 200-209.

[15] A. Criscuoli, E. Drioli, A. Capuano, B. Memoli, V. Andreucci, Human plasma ultrafiltrate purification by membrane distillation: process optimisation and evaluation of its possible application on-line, Desalination 147 (2002) 147-148.

[16] Z. Ding, L. Liu, Z. Liu, R. Ma, The use of intermittent gas bubbling to control membrane fouling in concentrating TCM extract by membrane distillation, J. Membr. Sci. 372 (2011) 172-181.

[17] C. Cabassud, N. Couffin, V. Lahoussine-Turcaud, A new process to remove halogenated VOCs for drinking water production: vacuum membrane distillation, Desalination 117 (1998) 233-245.

[18] M. Khayet, Treatment of radioactive wastewater solutions by direct contact membrane distillation using surface modified membranes, Desalination 321 (2013) $60-66$.

[19] H. Arafat, N. Thomas, M. Mavukkandy, S. Loutatidou, Membrane distillation research \& implementation: lessons from the past five decades, Sep. Purif. Technol. 189 (2017) 108-127.

[20] R. Schwantes, A. Cipollina, F. Gross, J. Koschikowski, D. Pfeifle, V. Subiela, M. Rolletschek, Membrane distillation: solar and waste heat driven demonstration plants for desalination, Desalination 323 (2013) 93-106.

[21] J. Assink, A. Jansen, J. Hanemaaijer, J. van Medevoort, E. van Sonsbeek,
Development and pilot testing of full-scale membrane distillation modules for deployment of waste heat, Desalination 323 (2013) 56-65.

[22] W. Heinzl, K. Zhao, M. Wenzel, S. Büttner, F. Bollen, G. Lange, S. Heinzl, N. Sarda, Experimental study of the memsys vacuum-multi-effect-membrane-distillation (VMEMD) module, Desalination 323 (2013) 150-160.

[23] T. Tong, The Gloval Rise of Zero Liquid Discharge for Wastewater Management: Drivers, Technologies and Future Directions, Menachem Elimelech, Environmental Science and Technology, 2016.

[24] T. Cath, J. Bush, J. Vanneste, Membrane distillation for concentration of hypersaline brines from the Great Salt Lake: effects of scaling and fouling on performance, efficiency, and salt rejection, Sep. Purif. 170 (2016) 78-91.

[25] J. Graham, Evaluation and selection of available processes for a zero-liquid discharge system for the perris, Desalination and Water Purification Research and Development Program Report No. 149, U.S. Department of the Interior, California, 2008.

[26] J. Gillron, Brine treatment and high recovery, Emerging Membrane Technology for Sustainable Water Treatment, Elsevier B.V., 2016, pp. 297-319.

[27] L. Eykens, T. Reyns, K. De Sitter, C. Dotremont, L. Pinoy, B. Van der Bruggen, How to select a membrane distillation configuration? Process conditions and membrane influence unraveled, Desalination 399 (2016) 105-115.

[28] D. Winter, Membrane Distillation - A Thermodynamic, Technological and Economic Analysis (PhD Thesis), http://www.reiner-lemoine-stiftung.de/pdf/ dissertationen/Dissertation-Winter.pdf University of Kaiserslautern, 2015.

[29] K.H. Mistry, Irreversibilities and Nonidealities in Desalination Systems (PhD Thesis), https://dspace.mit.edu/handle/1721.1/81703\#files-area Massachusetts Institute of Technology, 2013.

[30] H. El-Dessouky, H. Ettouney, Fundamentals of Salt Water Desalination, Elsevier, 2002.

[31] V.G. Gude, Energy consumption and recovery in reverse osmosis, Desalin. Water Treat. 36 (2011) 239-260.

[32] C. Fritzmann, State-of-the-art of reverse osmosis desalination, Desalination 216 (1-3) (October 2007) 1-76.

[33] G. Thiel, E. Tow, L. Banchik, H.W. Chung, J. Lienhard, Energy consumption in desalinating produced water from shale oil and gas extraction, Desalination 366 (2015) 94-112 Bd.

[34] R. McGinnis, N. Hancock, M. Nowosielski-Slepowron, G. McGurgan, Pilot demonstration of the NH3/CO2 forward osmosis desalination process on high salinity brines, Desalination 312 (2013) 67-74 Bd.

[35] Brine-concentrate treatment and disposal options report, Reclamation - Managing Water in the West, 2009.

[36] M. Mickley, Survey of High-recovery and Zero Liquid Discharge Technologies for Water Utilities, Water Reuse Foundation, 2008

[37] H2O - Die Experten für abwasserfreie Produktion (Online). Available: https:// www.wastewater-evaporator-h2o.com/innovations/vacudest-wastewaterevaporator-with-energy-recycling, Accessed date: 7 May 2016.

[38] Y. Wang, N. Lior, Thermoeconomic analysis of a low-temperature multi-effect thermal desalination system coupled with an absorption heat pump, Energy 2010 (2010).

[39] E. Drioli, Membrane distillation: recent developments and perspectives, Desalination 356 (October 2015) 56-84.

[40] M. Tomaszewsa, Mass transfer of $\mathrm{HCl}$ and $\mathrm{H} 2 \mathrm{O}$ across the hydrophobic membrane during membrane distillation, J. Membr. Sci. 166 (2000) 149-157.

[41] M. Tomaszewsa, Study on the concentration of acids by membrane distillation, J. Membr. Sci. 102 (1995) 113-122.

[42] P. Wang, T.-S. Chung, Recent advances in membrane distillation processes: membrane development, configuration design and application exploring, J. Membr. Sci. 474 (2015) 39-56.

[43] R.A. Tufa, E. Curcio, E. Brauns, W. van Baak, E. Fontanova, G. Di Profio, Membrane distillation and reverse electrodialysis for near-zero liquid discharge and low energy seawater desalination, J. Membr. Sci. 496 (2015) 325-333.

[44] Lawson, Lloyd, Membrane distillation. II. Direct contact MD, J. Membr. Sci. 120 (1996) 123-133.

[45] Z. Wang, F. Zheng, Y. Wu, S. Wang, Membrane osmotic distillation and its math ematical simulation, Desalination 139 (2001) 423-428.

[46] N. Ghaffour, A. Alsaadi, J.-D. Li, S. Grey, L. Francis, H. Maab, G. Amy, Modeling of air-gap membrane distillation process: a theoretical and experimental study, J. Membr. Sci. 445 (2013) 53-65.

[47] L. Zhang, M. El-Rady Abu-Zeid, W.-Y. Jin, T. Feng, Y. Wu, H.-L. Chen, L. Hou, Improving the performance of the air gap membrane distillation process by using a supplementary vacuum pump, Desalination 384 (2016) 31-42.

[48] S. Bandini, G. Sarti, C. Gostoli, Extraction of organic components from aqueous streams by vacuum membrane distillation, J. Membr. Sci. 80 (1993) 21-33.

[49] MVC evaporator capacities, Encon evaporators (Online). Available: http://www. evaporator.com/mvc-capacities , Accessed date: 6 January 2016.

[50] A. Hagedorn, G. Fieg, D. Winter, J. Koschikowski, A. Grabowski, T. Mann, Membrane and spacer evaluation with respect to future module design in membrane distillation, Desalination 413 (2017) 154-167.

[51] E. Guillen-Burrieza, Membrane structure and surface morphology impact on the wetting of MD membranes, J. Membr. Sci. 483 (2015) 94-103.

[52] M. Gryta, Fouling in direct contact membrane distillation process, J. Membr. Sci. 325 (November 2008) 383-394.

[53] D. Winter, J. Koschikowski, M. Wieghaus, Desalination using membrane distillation: experimental studies on full scale membrane distillation modules, J. Membr. Sci. 375 (2011) 104-112.

[54] J. Li, et al., Treatment of high salinity brines by direct contact membrane distillation: effect of membrane characteristics and salinity, Chemosphere 140 (2015) 
$143-149$.

[55] R. Bouchrit, et al., Direct contact membrane distillation: capability to treat hypersaline solution, Desalination 376 (2015) 117-129.

[56] L. Nghiem, H. Duong, A. Chivas, B. Nelemans, M. Duke, S. Gray, T. Cath, Treatment of RO brine from CSG produced water by spiral-wound air gap membrane distillation - a pilot study, Desalination 366 (2015) 121-129.

[57] E. Mohammed, Experimental evaluation of the performance and energy efficiency of a Vacuum Multi-Effect Membrane Distillation system, Desalination 408 (2017) 70-80.

[58] S. Adham, Field evaluation of membrane distillation followed by humidification/ dehumidification crystallizer for inland desalination of saline groundwater,
Desalination 398 (2016) 12-21.

[59] D. Winter, et al., Comparative analysis of full-scale membrane distillation contactors-methods and modules, J. Membr. Sci. 524 (2017) 758-771.

[60] D.Q. Kern, Process Heat Transfer, McGraw-Hill Book Company, 1965.

[61] A. Mabrouk, Steam, electricity and water costs evaluation of power desalination cogeneration plants, Desalin. Water Treat. 22 (1-3) (2010) 56-64.

[62] ENCON, Encon Evaporators (Online). Available: http://www.evaporator.com/ (Access on 2016).

[63] M. Mickely, Treatment of concentrate, Desalination and Water Purification Research and Development Programm Report No. 55, May 2009. 